ENSAYO

\title{
LA CONCEPCIÓN BENEVOLENTE PERO INTERESADA DE LA FILOSOFÍA DE ADAM SMITH*
}

\author{
Eric Schliesser
}

En este ensayo se explora la concepción que tiene Adam Smith de la filosofía y de la relación de ésta con la vida corriente (política/religión) y con la filosofía natural (ciencia). Primero se reseña la interpretación naturalista de Smith de la filosofía natural de Newton, contrastándola con las concepciones de Hume y Berkeley. Luego se explica el doble rol que Smith le atribuye a la filosofía: como fuente de consejos para el diseño de un marco institucional equitativo y como instrumento que puede ayudar a prevenir a la ciudadanía de las

Eric Schliesser. Ph.D., Filosofía, Universidad de Chicago. Profesor del Departamento de Filosofía en Syracuse University. Investigador Asociado, Amsterdam Research Group in History and Methodology of Economics. Coeditor con Leonidas Montes, New Voices on Adam Smith (Londres: Routledge, 2006). Ha publicado numerosos artículos en revistas especializadas.

* “Adam Smith’s Benevolent and Self-interested Conception of Philosophy”, publicado en New Voices on Adam Smith, Leonidas Montes y Eric Schliesser, editores (Londres: Routledge, 2006). Traducción al castellano de Estudios Públicos. Su publicación en esta edición cuenta con la debida autorización.

Agradezco a Christopher Berry, Doug den Uyl, Abe Stones, Maria Paganelli, Ryan Hanley, Sam Fleischacker, Fonna Forman-Barzilai, James Buchanan, Sandra Peart, David Levy, Larry Mary, Marilyn Friedman, Ali Khan, Steve Viner y a quienes en la Washington University hicieron útiles comentarios a una versión anterior de este trabajo. Asimismo, quisiera reconocer mi deuda con Lauren Brubaker y Spencer Pack por nuestras innumerables conversaciones acerca del concepto de filosofía de Smith. A Leonidas Montes habrá de acusarse por los errores que todavía pueda contener este capítulo.

Para las abreviaciones y referencias de las obras de Smith, véase sección a) de las referencias bibliográficas.

Estudios Públicos, 104 (primavera 2006). 
tendencias faccionarias y del fanatismo como consecuencia no deseada de la religión.

Finalmente se analiza la respuesta de Smith a Rousseau. Ésta procede en dos niveles: el primero concierne al entendimiento correcto del republicanismo moderno y el segundo al entendimiento correcto del punto de vista teórico. Se refuta aquí la difundida visión de Smith como un defensor irrestricto del mercado económico y del mercado de la moral. Se argumenta que Smith aprueba la vida comercial como un "medio" para hacer posible la filosofía y se analiza el debate con Rousseau, en particular el famoso pasaje sobre el "engaño" de la naturaleza en La Teoría de los Sentimientos Morales.

Las ideas no se producen de cualquier forma ni menos al azar, hay cierto orden y relación entre ellas como entre causa y efecto; también hay diversas combinaciones de ellas que han sido concebidas de un modo muy regular y artificial y que, como tantos otros instrumentos en manos de la naturaleza que están ocultos, por así decirlo, tras el escenario, participan en forma secreta en la producción de las apariencias que se observan en el teatro del mundo y que sólo son discernibles para el ojo curioso del filósofo. (George Berkeley, Principios del Conocimiento Humano, Sección 64.)

\section{E} Adam Smith del rol de la filosofía y, especialmente, de su relación con la vida común (cómo se manifiesta en la política, la religión, la opinión pública, etc.) y con la filosofía natural (es decir, la ciencia). Postulo que la visión que tiene Smith del problema tradicional entre la filosofía y la sociedad, es decir, el Problema Socrático — con lo que me refiero a que el pensamiento libre y racional puede verse menoscabado por diversas exigencias sociales-, así como el problema más reciente, aquel de una ciencia dotada de autoridad por encima de la filosofía — el desafío de Newton-, pueden comprenderse mejor a la luz de la discusión de Smith respecto al cuestionamiento que hace Rousseau de la valía de la sociedad comercial.

En la sección siguiente argumento en contra de las afirmaciones de que el concepto de ciencia de Smith sería baconiano (es decir, en torno de la utilidad) y que él niegue que la filosofía sea un fin en sí misma. En la tercera sección esbozo la respuesta de Smith respecto al éxito de la ciencia. A diferencia de Berkeley o de Hume, no persigue Smith restringir o reinterpretar los títulos de la ciencia. Él adopta un punto de vista teórico en el que los resultados de la ciencia son examinados de modo crítico y eventualmen- 
te aprobados. En la cuarta sección explico el doble papel político que para Smith tiene la filosofía: como consejera de estadistas, la filosofía contribuye al diseño de una estructura institucional equitativa; $y$ al interior de la sociedad, la filosofía puede ayudar a inmunizar a los ciudadanos contra los peligros de la religión y del sectarismo.

La sección final analiza la multifacética respuesta de Smith a Rousseau. Sostengo que Smith ataca la "filosofía abstracta" de Rousseau, especialmente su defensa de la autosuficiencia. La discusión de Smith con Rousseau acontece en a lo menos dos niveles: uno se refiere a la correcta comprensión del republicanismo moderno y el otro concierne a la correcta comprensión del punto de vista teórico. Mi tesis pone en tela de juicio concepciones frecuentes acerca de la filosofía de Smith, esto es, aquellas que ven en este pensador un simple defensor del mercado de la moral y del mercado de la economía política (p. ej. Otteson, 2002). Sostengo, por el contrario, que Smith más bien aprueba la vida comercial como medio para la filosofía.

\section{Curiosidad y admiración por los filósofos}

En esta sección argumento que Smith plantea una tesis antibaconiana respecto al origen y uso de la filosofía. (En tiempos de Smith, “artes”, "ciencias” y "filosofía” podían tener connotaciones más amplias y estar más cerca de ser sinónimos; véase, p. ej., “Astronomy”, II, I2, 46. Para un análisis de este asunto, véase Buckle, 1999: 7-8, aunque está centrado particularmente en Hume.) Es más, aun cuando los filósofos puedan creer que se diferencian del grueso de la humanidad común y corriente, de acuerdo con Smith la filosofía es solamente una ocupación más entre muchas otras. En el primer capítulo del primer libro de La Riqueza de las Naciones $(R N)$, Smith destaca que los filósofos forman parte de la división del trabajo ( $R N$ I.i.9, 2122); poco después hace escarnio de la vanidad de los filósofos por pensar lo contrario ( $R N$ I.ii.4, 29). De modo que Smith sigue a Hume cuando sostiene que la filosofía acontece al interior de la sociedad (véase Hanley, 2002, y para un argumento diferente, Schliesser, 2003). Como postula Smith en "La Historia de la Astronomía” (“Astronomy”), la filosofía surge "cuando el derecho ha impuesto orden y seguridad y la subsistencia deja de ser precaria, cuando se ha incrementado la curiosidad de la especie humana y ha disminuido su temor. El ocio del que entonces disfrutan los hombres los vuelve más atentos a los fenómenos de la naturaleza” "“Astronomy” III.3, 50). Por lo tanto, la invocación que hace Smith de la filosofía como una más entre otras actividades y su énfasis en que no hay diferencia entre "un filósofo y un mozo de carga cualquiera" $(R N$ I.ii.4, 28) indican al inicio de $R N$ que su teorización también se aplica al "oficio y ocupación” de la "especu- 
lación” ( $R N$ I.i.9, 21; sobre este tema, véanse Levy, 1988 y 1992; Peart y Levy, 2005).

De acuerdo con Smith, el oficio del filósofo consiste en "no hacer nada pero observarlo todo; y son los filósofos quienes, por esta razón, a menudo son capaces de combinar las fuerzas de los objetos más distantes y disímiles" ( $R N$ I.i.9, 21). La referencia nada de escéptica a unas “fuerzas” es newtoniana ${ }^{1}$; coincide con su tendencia general a adoptar el esquema de Newton. Por ejemplo, en su ensayo "Of the External Senses", Smith describe a los planetas como "masas en movimiento" (EPS 12, 137). Sostengo en otra parte que en una de sus principales argumentaciones en defensa de los postulados de Copérnico, Smith acepta tácitamente los criterios de Newton para evaluar las razones de la anterior comunidad de filósofos naturales, aun cuando el propio Newton estaba dispuesto a emplear argumentos que apelaban al antiguo conjunto de normas (“Astronomy” IV.58, 90-91 y IV.67, 98; Schliesser, por publicar). Smith no intenta evitar la discusión de la acción-a-la-distancia de Newton²; explica cómo la teoría de Newton supone una atracción universal, mutua y simultánea entre los planetas y el sol (“Astronomy”, IV, 67-76, 98-104). Smith se da cuenta de que se puede concebir "la luna como en permanente caída sobre la tierra" y habla libremente de la "mutua atracción entre los planetas" (“Astronomy” IV, 67-68, 99; sobre Newton y Smith, véanse los esfuerzos pioneros de Montes 2003; véanse también Montes 2006 y Schliesser 2005b).

Muchos han querido ver una posición escéptica en la interpretación psicológica que da Smith a la aceptación de una teoría (Cremaschi, 1989; Pack, 1991: 114; Griswold, 1999: capítulos 4, 8, y epílogo; Rothschild 2002:138-140, 229). Es cierto que los ejemplos que da Smith de la aceptación de las fuerzas invisibles son compatibles con un tipo de "realismo escépti-

${ }^{1}$ Véase el "Prefacio" de Newton para los Principia: "Considero a la filosofía [...] y no escribo sobre las fuerzas manuales sino que sobre las naturales, y considero en lo principal aquellas cosas que se relacionan con la gravedad, la levedad, la fuerza elástica, la resistencia de los fluidos y fuerzas semejantes, ya sean por atracción o impulsión; y por ello ofrecemos este trabajo como principios matemáticos de la filosofía, pues toda la carga de la filosofía parece consistir en esto: investigar las fuerzas de la naturaleza a partir del fenómeno del movimiento y luego describir, a partir de esas fuerzas, el resto de los fenómenos".

${ }^{2}$ El trabajo de Mirowski (1989, 164), si bien ampliamente difundido (además de entretenido), es altamente engañoso cuando sugiere que Smith quería desviar nuestra atención de la acción-a-la-distancia de Newton. Mirowski no sólo cita dos pasajes fuera de contexto (en que no hay mención alguna a Newton), sino que además no hace referencia a pasajes en que Smith ¡discute los principios de Newton! A partir del relato de Mirowski jamás llegaríamos a saber que, aparte de los pasajes citados en el texto, Smith también escribió que "[Newton] demostró que si los planetas gravitan en torno al sol y uno en relación al otro [...]” (“Astronomy” IV.67). 
co" que recientemente ha sido atribuido a Hume (Wright, 1983). Pero aun cuando esto no puede ser descartado, en "Astronomy" hay un ejemplo muy sorprendente y escasamente considerado del rechazo por parte de Smith del escepticismo al estilo de Hume. En EHU 4.2.16 Hume se refiere a la fuente desconocida del carácter nutritivo del pan como ejemplo de nuestra "ignorancia de las fuerzas naturales", esto es, de cómo la "naturaleza nos ha mantenido a gran distancia de todos sus secretos". Hume interpreta los avances de Newton en general como una confirmación de esta concepción. En su The History of England escribe: "Mientras Newton parecía remover los velos de una parte de los misterios de la naturaleza, al mismo tiempo puso de manifiesto las imperfecciones de la filosofía mecánica; y con ello restituyó sus secretos elementales a esa oscuridad en que siempre permanecieron y por siempre permanecerán” (VI, 542; cursivas agregadas). Hume se refiere a la refutación que hace Newton de la filosofía mecánica como evidencia decisiva para la afirmación de que la naturaleza permanecerá en principio inescrutable ${ }^{3}$ (en $E H U$ 4.1.12, Hume también restringe lo que serán "las causas y los principios primordiales que alguna vez habremos de descubrir en la naturaleza", aunque en el contexto baja un tanto sus apuestas). En su "Astronomy", Smith circunscribe cuidadosamente el "nosotros" implícito en el ejemplo del pan que da Hume. Smith discute el ejemplo solamente como una instancia de la diferencia entre el "grueso de la humanidad" y los "filósofos". Los primeros "rara vez han sentido curiosidad por inquirir" cómo el pan se "transforma en carne y huesos", mientras que los segundos han intentado hallar el "eslabón" de la cadena que pueda explicar la "nutrición del cuerpo humano". Smith trata este ejemplo no como confirmación de un tipo de escepticismo fundamental respecto al conoci-

${ }^{3}$ Buckle (2003: 85 y sig.) interpreta los comentarios de Hume como ecos de las famosas hipótesis non fingo de Newton y, por eso, considera que la postura de Hume (sea instrumental o realista escéptica) es compatible con la de Newton. A mi entender, Hume acierta cuando afirma que, a la luz del propio Newton (y también en el hecho), Newton había "demostrado las imperfecciones de la filosofía mecánica”. Pero Buckle no se da cuenta de que la hipótesis non fingo es un rechazo a las normas de evaluación y, especialmente, a los criterios de inteligibilidad promovidos por la filosofía mecánica. Según Newton se puede aceptar la realidad e inteligibilidad de las fuerzas aun cuando no se pueda dar una descripción "físico-mecánica” (para recurrir a la terminología de Kant); esto es así porque Newton mismo rechaza que sea necesario. Pero esto no significa que para Newton los secretos de la naturaleza quedarían, en principio, para siempre vedados al conocimiento. (Como revelan las preguntas de su Opticks, Newton piensa que vale la pena especular en torno de todo tipo de potenciales explicaciones causales de los fenómenos.) De modo que se iría demasiado lejos si se afirma que Newton piensa que no hay necesidad de mirar más allá en busca de otras causas subyacentes, o que éstas seguirán sin respuesta por razones epistemológicas (Cf. Strawson 2002: 237 y 247-248). Agradezco a William Vanderburgh por su discusión. 
miento posible de la naturaleza, sino más bien como un problema de investigación no muy diferente del que intenta "relacionar la gravedad, elasticidad e incluso la cohesión de los cuerpos naturales con algunas de sus otras cualidades" (“Astronomy” II.11. 44-45; "la filosofía es la ciencia de conectar principios de la naturaleza”, II.12, 45). De modo que la respuesta al ejemplo de Hume muestra que, para Smith, hay cierta diferencia entre el "grueso de la humanidad" y los "filósofos" que se manifiesta en una disimilitud en la curiosidad. Esa disparidad es en gran medida un efecto de la división del trabajo, procedente del "hábito, la costumbre y la educación" ( $R N$ I.ii.4, 2829). En contraste, veamos lo que afirma el eminente académico Sam Fleischacker: "Smith jamás sugiere en alguno de sus escritos que pudiera haber una diferencia entre las creencias de la 'vida común' y las visiones de los filósofos, como sí lo hace su amigo David Hume” (Fleischacker, 2004: 15). Sin compartir la "cacería" de "doctrinas esotéricas" en Adam Smith (el objetivo de Fleischacker en el contexto de su cita), este ensayo es, pues, una amplia crítica de la posición de Fleischacker.

De acuerdo con Smith, en ocasiones la labor e ingenio de los filósofos conducen a "mejoramientos en las maquinarias"; presumiblemente debido a su capacidad de combinar "entre sí las fuerzas" de objetos distantes. No cabe duda de que es este dominio de la naturaleza con los dispositivos tecnológicos lo que ha llevado a ciertos comentaristas perspicaces a atribuir a Smith una comprensión de la filosofía al modo de Bacon (véase Berry —por publicar-y la visión más amplia defendida en Berry, 1997: 53 y sig.). Pero esto es engañoso. Primero, sólo "algunos" de los mejoramientos son atribuidos a hombres de especulación, mientras "muchos" se deben a los "fabricantes de las máquinas" ( $R N$ I.i.9, 21). Es más, en La Teoría de los Sentimientos Morales (TSM) la tendencia a enfatizar la utilidad de las "ciencias más abstrusas” se explica como una respuesta retórica post-facto en desaprobación de aquellos que "no tienen gusto por tan sublimes descubrimientos". (Tal vez el objetivo de Smith sea la manera en que Hume se refiere a Newton en su "Of the Middle Station of Life"). Claro que las ciencias pueden tener alguna utilidad: "La utilidad de esas ciencias, sea para el individuo o para el público, no es muy obvia, y probarlo requiere de una discusión que no siempre es fácilmente comprendida” ( $R N$ IV.2.7, 189). Pero éste no es el punto central. La visión baconiana no calza con la descripción que da Smith del origen de la ciencia. Al contrario de Rousseau, por ejemplo, quien afirma que las ciencias son "engendradas en el ocio" (Discourse on the Sciences and Arts, Parte II,39, OC III, 18), Smith insiste en que el perturbador sentimiento de sus descubrimientos, es lo que constituye el primer principio 
que impulsa al género humano al estudio de la filosofía [...] y [ellos] emprenden ese estudio por su bien en sí, como un placer inusual o un bien en sí mismo, sin tener en cuenta su tendencia a procurarles los medios para otros placeres ("Astronomy”, III.3, 51) ${ }^{4}$.

Para Smith, la filosofía apunta originalmente a calmar la imaginación: "La filosofía [...] intenta introducir orden en el caos de las irritantes y discordantes apariencias, busca apaciguar este revuelo de la imaginación” (“Astronomy” II.12, 45-46).

En $R N$, cuando Smith discute la "filosofía moral y natural” ( $R N$ V.i.f.26, 767-770), enfatiza, haciéndose eco de su “Astronomy”, cómo ambas se originan en la curiosidad y el asombro ( $R N$ Vi.f.25) y apelan a la "belleza de un arreglo sistemático” ( $R N$ V.i.f.25, 768; acerca de la importancia de la belleza y las consideraciones estéticas en la ciencia y la filosofía, véanse también TSM I.i.4.3, 20 y “Astronomy” IV.13, 62). Smith señala que los "hombres de teoría son aficionados a las paradojas y a aparentar entender aquello que sobrepasa la comprensión de la gente común” ( $R N$ IV.ix.38, 678679; véase también “Astronomy”, IV.33, 75). Es la “admiración” la que nos permite aplaudir las "virtudes intelectuales” (TSM I.i.4.3, 20; sobre la "admiración”, véase también “Astronomy”, Intro, 5-7, 34 y IV.5, 56, etc., $R N$ IV.ix.38, 678-679; véase Schliesser, por publicar) ${ }^{5}$. Dado que la filosofía es tan sólo una entre muchas ocupaciones, su descripción del asombro coincide muy bien con la psicología de la ambición "profesional” en $R N$, que es articulada en términos del deseo de emular y del afán de obtener la admiración pública ( $R N$ V.i.f.4, 759-760; I.x.b, 23-25, 123-124).

De modo que tanto $R N$ como TSM y “Astronomy” coinciden todas en negar la importancia del enfoque baconiano respecto al origen y los

\footnotetext{
${ }^{4}$ Este pasaje es ignorado por aquellos, como por ejemplo Cropsey (1957: 7-9) y Griswold (1999), que afirman que Smith pensaba que la filosofía no es un fin en sí. Esa postura parece ser sugerida en TSM I.i.4.5, 21, donde sin embargo concluye: "La idea de la utilidad de todas las cualidades de este tipo [esto es, los sentimientos intelectuales] es claramente algo que se nos ocurre después y no lo que primero las recomienda para nuestra aprobación”. Para observaciones útiles, véase Fleischacker (2004: 69).

${ }^{5}$ A veces se dice (véanse las referencias a Cropsey y Griswold en la nota anterior) que Smith descuida los sentimientos intelectuales en TSM, pero como muestra mi discusión anterior y posterior de TSM I.i.4.3, 20, Smith introduce el examen de éstos y de la vida teórica al comienzo de TSM. Dado que diagnostica la hostilidad de la sociedad hacia la vida teórica (véase mi análisis de "Astronomy” IV.4, 55-56; $R N$ V.i.f.4; TSM IV.2.7, 189, abajo), su relativa reticencia a explorarla más a fondo en un trabajo destinado a un público más amplio coincide con su punto de vista general.
} 
objetivos de la filosofía. No es la "utilidad" o el amor por la ganancia lo que impulsa y mantiene la actividad teórica. Por el contrario, el amor por la paradoja, el asombro, la admiración y la belleza constituyen importantes motores de motivación. Más aún, la actividad especulativa es un intento de ciertas personas curiosas para situarse al margen de las personas corrientes. Sin embargo, esto no es más que "vanidad".

Claro que Smith está de acuerdo con Hume (cf. "The Rise and Progress of the Art and Sciences") respecto a que en el transcurso del "progreso de la sociedad" la filosofía se convierte en una actividad especializada, en sí "dividida en una gran cantidad de ramas diferentes, cada una de las cuales provee de ocupación a una tribu o clase peculiar de filósofos" ( $R N$ I.i.9, 21-22). En efecto, sólo después del "avance del refinamiento", es decir, en una fase relativamente tardía de la civilización, la "filosofía y la retórica se pusieron de moda". Es entonces cuando "el mejor tipo de personas [...] envía a sus hijos a las escuelas de los filósofos y retóricos con el fin de que sean instruidos en las ciencias que están en boga ( $R N$ V.i.f.43, 777). La división del trabajo que posibilita el crecimiento de la riqueza crea las condiciones que estimulan el interés por la filosofía, el que debe ser cultivado (“durante mucho tiempo", "la demanda” que tuvo "fue escasa”, $R N$ V.i.f.43, 777). Una vez que hay mayor demanda por la filosofía se hace posible la división del trabajo al interior de ella misma, lo que en ocasiones conduce a mejoramientos en las máquinas que a su vez aumentan la productividad y amplían la división del trabajo y el círculo virtuoso de la riqueza (opulence). Todo esto apunta a establecer los deslindes de la filosofía como una más entre otras actividades de la sociedad.

Por otro lado, para Smith al menos ciertos tipos de filosofía (moral) responden a su entorno. La "Introducción" al Libro IV de $R N$ parece dar a entender que los contenidos de los "sistemas" de economía política son el resultado de factores sociales y temporales difusos. En cierto modo representan el estado de "progreso de la opulencia" ( $R N$ IV Introducción 2, 428). Por extraño que parezca, Smith deja sin explicar cuáles factores influyeron en su teoría.

Una vez que se ha llevado a cabo la especialización entre los filósofos, uno podría preguntarse cómo es posible "observarlo todo” y combinar “conjuntamente las fuerzas de los objetos más distantes y disímiles”. Después de todo, Smith enfatiza al comienzo de $R N$ que la división del trabajo hace que tengamos vistas muy parciales del todo ( $R N$ I.1.2, 14; véase Levy, 1995; Schliesser, 2005b). En consecuencia, ¿cómo pueden los filósofos ser propiamente filósofos si participan de la división del trabajo? Este tema se 
vuelve tanto más apremiante cuando se piensa que la filosofía meramente representa el "progreso de la opulencia" individual del filósofo. Dada la definición que Smith nos entrega de la filosofía, ¿qué pretensión puede ella tener de ser comprehensiva* y verdadera? Debido a que las propias ambiciones de Smith en cuanto a ser un filósofo sistemático fueron anunciadas en el último párrafo de la primera edición de TSM (1759) y refrendadas en el “Advertisement” de la última edición (1790; allí desea "continuar con la obligación de hacer" lo que pueda), podemos formular este punto como un problema relacionado con la forma en que Smith entiende su propia actividad teórica.

Por otro lado, de Sócrates en adelante la relación de la filosofía con la sociedad no se encuentra tan exenta de problemas como Smith parece sugerir. No es sólo la "vanidad" de los filósofos la que los conduce a pensar que son diferentes del grueso de la especie humana. Incluso las sociedades más libres, como la Atenas clásica, por ejemplo, pueden reaccionar en forma negativa a las actividades de los filósofos. (Es ésta la noción subyacente al diálogo de la Sección XI en el primer Enquiry de Hume.) Smith lo sabe. Escribe, por ejemplo, que en "tiempos antiguos algunos filósofos de la 'Escuela Italiana’ sólo enseñaban sus doctrinas a los discípulos bajo el más sagrado de los secretos, para que evitasen la furia del pueblo y no se les acusase de ser impíos” (“Astronomy” IV.4, 55-56) ${ }^{6}$. Las "escuelas" de los filósofos "no eran respaldadas por el público. Durante largo tiempo apenas fueron toleradas por éste” ( $R N$ V.i.f.43, 777). En efecto, como indica Smith (recuérdese TSM IV.2.7, 189), incluso podría pensarse que el énfasis de los filósofos en la utilidad de su actividad era precisamente la respuesta retórica que exigía la desaprobación social de la filosofía (cf. $R N$ V.i.f.43, 778). Cuando Smith fue profesor en Glasgow dictó un curso regular de retórica; estaba consciente de su poder (Ross, 1995: 128 y sig.; para una discusión importante, véanse Brown, 1994 y Fleischacker, 2004: 12-15). En las dos secciones siguientes explico la actitud de Smith, primero respecto a la teorización y después en relación con la vida política.

* En el sentido de “abarcadora”. (N. del T.)

${ }^{6}$ En otro ensayo, “Ancient Physics” $(9,113)$, Smith destaca que los pitagóricos fueron miembros de una "secta que en el mundo antiguo jamás fue considerada irreligiosa”. Smith nunca deja en claro que los pitagóricos fueran aquella "escuela italiana” mencionada en "Astronomy". En su debido contexto, el fraseo de Smith parece sugerir que en tiempos modernos los pitagóricos fueron considerados ateos. (Para un punto de vista similar, véase cómo se refiere Hume al politeísmo en el capítulo IV de Natural History of Religión.) 


\section{La posición de Smith respecto a la teorización ${ }^{7}$}

El inesperado éxito de la filosofía natural de Newton amenazó la autoridad independiente de la filosofía, especialmente porque desde el punto de vista de la filosofía mecánica reinante la filosofía era incapaz de justificar los métodos de Newton o de ofrecer una explicación del éxito de Newton en los primeros principios. Por vez primera un naturalismo motivado por el éxito empírico de la ciencia se vuelve respetable. Desde luego, no pretendo decir que no hubiera formas anteriores de naturalismo. Pero, por ejemplo, el fisicalismo de Aristóteles fue motivado por sus primeros principios (véase Metafísica E.1.1026a27-9). Berkeley y Hume intentaron restablecer la autoridad de la metafísica sobre la filosofía natural por la vía de limitar las pretensiones de la ciencia o de reinterpretar su lenguaje. Para Berkeley y Hume, las teorías científicas eran herramientas muy sofisticadas para hacer predicciones, y la interpretación de éstas estaba subordinada a consideraciones filosóficas. Pero no podían hacer justicia ni al contenido ni al atractivo de la filosofía natural de Newton (véase Schliesser, 2004, s/f. a, b). Como se ha dicho en la segunda sección, Smith acepta el esquema newtoniano. En esta sección explico el concepto que tiene Smith del punto de vista teórico en respuesta al éxito de la filosofía natural y cómo se relaciona ese punto de vista con la vida común.

El elemento social y discursivo de la ciencia

La psicología moral de Smith gira en torno a la idea de que las personas son por naturaleza animales sociales. Desde muy temprana edad ellas son juzgadas por otras personas y una vez que se hacen conscientes del hecho, ellas proceden, a su turno, a juzgar tanto a las personas de su entorno como a sí mismas (TSM III.i.2-6, 109-113). Esto se ve facilitado por el proceso de la "simpatía” — aquel mecanismo de la imaginación por el cual sentimos empatía con los sentimientos de otros (TSM III.1.2, 109 y I.1.1.5, 10; véanse Griswold 1999: capítulo 2; Otteson, 2002: capítulos 2-3). Smith piensa que las personas desean ser elogiadas por los demás y, más importante todavía, quieren entender su propia conducta como digna de elogio (TSM III.ii, 113-134). En todas las profesiones, la "rivalidad y la emulación hacen que la excelencia se vuelva un objeto a ambicionar y dan lugar con

${ }^{7}$ El argumento de esta sección descansa principalmente en Schliesser (por aparecer), texto en donde hago una descripción más extensa del papel epistemológico del espectador imparcial. 
frecuencia a los más grandes esfuerzos” ( $R N$ V.i.f.4, 759-760). La conclusión de esta descripción compleja y desarrollista es que todas las personas, incluyendo a los filósofos, habitualmente desean y buscan la aprobación de los demás, siendo ésta la fuente de nuestra vanidad, ambición y moral. Los filósofos pueden verse motivados por el deseo de fama (TSM III.2.8, 117; D’Alembert, 1995: 93, tampoco tiene dudas al respecto. Acerca del amor y la amistad como recompensa de la virtud, véanse Cropsey, 1957: 51-52; Brubaker, 2003; Uyl y Griswold, 1996; Schliesser, 2003). Smith afirma que nos comportamos de maneras que esperamos cosechen aplausos o la aprobación de otros (TSM III.i.5, 112). A medida que crecemos, internalizamos los valores y las expectativas de nuestra comunidad o de la opinión pública. Nos comportamos como si fuésemos observados y juzgados por un "Espectador Imparcial”. Mientras destaca la importancia de la imaginación, Smith escribe: "Aquí, como en todos los demás casos, debemos vernos a nosotros mismos [...] de acuerdo a como naturalmente aparecemos ante los demás” (TSM II.ii.2.1, 83). Smith no es ingenuo: piensa que, en general, "nos inclinamos por naturaleza a sobrestimar las excelencias de nuestro propio carácter" (TSM III.2.34, 133). Smith está consciente de los riesgos del "autoengaño, esa fatal debilidad de la estirpe humana” (TSM III.4.6, 158; véase Gerschlager, 2002).

Ese juez imaginario en nuestro interior, “temible y respetable”, puede ayudarnos a corregir los estándares de nuestra comunidad cuando deseamos ser dignos de elogio (TSM III.2.24-30, 126-128). Ese deseo, basado en nuestro natural deseo de simpatía mutua y el natural amor por la virtud, es el paso crucial de la teoría de Smith (para un excelente tratamiento de este tema, véase Hanley, por publicar). Smith sitúa la fuente de ese deseo - que la aprobación que recibamos sea merecida - en la fundamental incertidumbre epistémica que cada uno de nosotros siente acerca de sus propios juicios (TSM III.2.24; III.2.28, 126-127, y “Astronomy” II.4, 40). Nuestro deseo por el tipo correcto de aprobación se origina en nuestro reconocimiento de la falibilidad de la autoridad de la persona interior. La filosofía de Smith se aparta de la confianza del ego cartesiano. Una de las razones de esto estriba en la dificultad de aplicar el estándar de evaluación correcto a nosotros mismos y en la facilidad con que nuestros sentimientos morales son corrompidos (p. ej., TSM I.iii.3, 61-66 y mi tratamiento de TSM VI.iii.23-26, 247-248, más abajo). Para Smith, aprender a verse uno mismo a la luz adecuada es en sí un logro cultural e intelectual que está al alcance de sólo unos cuantos de nosotros (TSM III.2.8, 117).

De modo que la imaginación no sólo es la fuente de nuestra creatividad para la construcción de sistemas científicos, sino que también la fuente 
de nuestra potencial imparcialidad para evaluarlos. Smith explica cómo los individuos han interiorizado —-mediante diversos medios de socialización y educación - una versión idealizada y posible de ser corregida de los valores y las expectativas de las comunidades a las que pertenecen.

Si se es miembro de una comunidad con estándares aceptablemente exactos y claros y las propias acciones coinciden con esos valores, disminuye la necesidad de una manifiesta aprobación pública debido a que se percibe un sentido de autoaprobación y de seguridad en la propia conducta. Uno sabe, tal como Smith pensaba que "posiblemente" era el caso de Newton, que se es loable incluso en ausencia del elogio público: la mente se siente tranquila en su "independencia" (TSM III.2.20, 12 y sig.; III.3.30, 149152).

Smith piensa que el éxito en las matemáticas o la filosofía natural admite "ya sea una clara demostración o una prueba muy satisfactoria" (TSM III.2.18, 123; IV.2.7, 189). Una vez que los matemáticos y los filósofos naturales han interiorizado los criterios y los métodos de una "demostración clara, o de una prueba muy satisfactoria" validada por sus disciplinas, no necesitan preocuparse de la opinión pública — dado que ya han adoptado la perspectiva del Espectador Imparcial—. Smith no piensa que los matemáticos o los filósofos naturales sean mejores que otras personas en cuanto a capacidad de interiorizar normas; sólo hay criterios más claros en estas áreas.

Pero en ocasiones hay criterios en pugna. Por ejemplo, en su "Astronomy", Smith destaca que el sistema de Copérnico fue aceptado "sólo por astrónomos", pero que "los doctos en todas las demás ciencias siguieron mirándolo con el mismo desdén del vulgo" (“Astronomy” IV. 36, 77) ${ }^{8}$. Smith piensa que "la coherencia conferida a los cuerpos celestes, la simplicidad y la uniformidad que introdujo a las verdaderas direcciones y a las velocidades de los planetas" atrajeron a los astrónomos al sistema de Copérnico, que "de feliz modo conectaba a los más distantes e inconexos objetos". Entretanto, los filósofos que se ocupaban del movimiento terrestre improvisaban objeciones en su contra (“Astronomy” IV. 38, 77-79). Esto postergó la adopción de la hipótesis copernicana. Vemos entonces que enfoques centrados en diferentes campos de estudio pueden llevar a grupos diversos de expertos a adoptar diferentes estándares de pruebas y sistemas (véase

${ }^{8}$ Los editores de "Astronomy” censuran a Smith por esta afirmación. Ellos ignoran la importancia que tiene el compromiso astronómico con Copérnico en la actitud filosófica general de luminarias como Stevin, Galileo, Gilert y Kepler, quienes insólitamente fueron todos copernicanos desde muy temprano, ya a fines del siglo dieciséis. Una obra muy provocativa sobre el tema es la de Margolis (2002). 
Skinner, 1996: 44). Smith reconoce que en ocasiones la teoría mejor no necesariamente concita aceptación entre los que no son especialistas y el "vulgo" (“Astronomy” IV.35-8, 76-78), que enarbolan, por ejemplo, el "prejuicio de la especie humana" y el "prejuicio del sentido, confirmado por la educación”, en contra del copernicanismo. Los filósofos son vulnerables a los "prejuicios" del vulgo; cuando son "naturales", pueden incluso corromper el pensamiento de Aristóteles, el más "renombrado filósofo" (“Ancient Physics” 10, 116).

Smith no ignora la situación en que filósofos naturales como Descartes, Galileo o Newton intentan cambiar criterios o establecer nuevos criterios para la comunidad científica. Él está consciente de la existencia de aquellos legisladores científicos:

La inteligencia aguda y delicada de la persona de buen gusto, que distingue las diminutas y apenas perceptibles diferencias de la belleza y la deformidad; la exactitud comprehensiva del matemático experimentado, que revela con facilidad las más intrincadas y confusas proporciones; el gran líder de la ciencia y el gusto, el hombre que dirige y conduce nuestros propios sentimientos, cuyos amplios y muy exactos talentos nos llenan de asombro y sorpresa, ésa es la persona que despierta nuestra admiración y parece merecedora de nuestro aplauso: y sobre estos fundamentos se basa la mayor parte del elogio conferido a las llamadas virtudes intelectuales (TSM I.i.4.3, 20; cursivas agregadas).

Smith vincula entre sí la capacidad del legislador científico de resolver problemas, de introducir criterios y de ganarse la admiración de otros. El "gran líder de las ciencias" no es un mero constructor de teorías o un experto en resolver problemas; es quien comprende las normas vigentes de una manera fundamental. Smith también da a entender que "el líder [...] que dirige y conduce nuestros propios sentimientos” fija estándares para ser emulados por otros ${ }^{9}$. Algunos de los grandes científicos no siguen meramente los valores existentes, sino que introducen nuevos estándares. Smith los describe como "las personalidades más espléndidas, aquellas gentes que han realizado los actos más ilustres, que han llevado a cabo las mayores revoluciones tanto en las situaciones como en las opiniones de los seres humanos” (TMS VI.iii.28, 250). De modo que cuando un filósofo natural contempla y presenta sus resultados, esto entraña una referencia a las normas de su comunidad: el Espectador Imparcial interior anticipa cómo el

${ }^{9}$ De acuerdo al Oxford English Dictionary, en tiempos de Smith "dirigir” puede significar "guiar/encauzar con consejo" o "dar instrucciones con fundamento". 
público (idealizado) de un científico juzgará una nueva teoría, y proporciona “autoaprobación” (TSM III.2.3, 114) y tranquilidad (“Astronomy” IV.13, 61). Claro que cuando un filósofo natural propone cambios en los estándares de una comunidad, sólo cabe esperar esa tranquilidad si él supone que el Espectador Imparcial aprobará con el tiempo las mejoras realizadas; en ocasiones la propia imaginación proyectará esa aprobación hacia la posteridad (TSM I.iii.1.14, 48-49 y VI.iii.5, 238-239). Es más, hay dos tipos de estándares que usamos para juzgar los propios esfuerzos:

Uno es la idea de la exacta corrección [propriety] y perfección, en tanto cada uno de nosotros sea capaz de comprender esa idea. El otro es aquel grado de aproximación a esta idea que comúnmente se alcanza en este mundo y que ya puede haber sido alcanzado por la mayor parte de nuestros amigos y compañeros, y rivales y competidores. Muy pocas veces (me inclino por decir que nunca) intentamos juzgarnos a nosotros mismos sin prestar más o menos atención a estos dos estándares diferentes [...] En todas las artes liberales e ingeniosas, en la pintura, la poesía, la música, la elocuencia, en la filosofía, el gran artista siempre percibe la imperfección real de sus mejores obras y es más consciente que cualquier otro hombre de hasta qué punto están lejos de esa perfección ideal que él de alguna forma ha concebido, que imita lo mejor que puede pero que ha perdido toda esperanza de igualar [...] Dijo Boileau, ningún gran hombre queda nunca completamente satisfecho con sus obras (TSM VI.iii.23-6, 247-248).

De ahí que, según Smith, el gran científico sólo queda satisfecho cuando (por un breve espacio de tiempo) compara su propia obra con aquella de sus pares, es decir, cuando dirige su atención hacia el segundo estándar. El primer estándar siempre puede inspirar reflexión crítica. Sin embargo, la teoría de Smith no dice cuál es la fuente de esa "idea de la exacta corrección y perfección"; él meramente asume que todos los individuos, o las subculturas a las que ellos pertenecen, tienen acceso a alguna noción de esa clase. (Puede que haya pensado que el problema quedó resuelto en el Treatise de Hume, 1.2.4.24-5.) ${ }^{10}$ Pero la advertencia de Smith de que en ocasiones juzgamos nuestros propios esfuerzos y los de otras personas con un estándar de corrección y perfección exactas no es suficientemente

${ }^{10}$ Hume muestra cómo las personas pueden construir "naturalmente” estándares "imaginarios" de la perfección. El ensayo de Hume, "Of the Dignity or the Meanness of Human Nature" contiene una discusión de varias fuentes de nociones de la perfección (cf. Treatise 1.2.4.29 para matices). Véase Frasca-Spada (1998: 44-45). 
apreciada por aquellos que se preocupan de la vía por la que podría desarrollarse en la psicología o epistemología de Smith una posición crítica ${ }^{11}$. Para Smith, la "imperfección real” está presente en todas las obras del hombre, de modo que siempre habrá espacio para la crítica (véase también TSM I.i.5.8, 25). Es ésta la fuente de la adhesión de Smith al falibilismo.

En efecto, la posibilidad de la crítica es crucial para entender el concepto que Smith tiene de la ciencia y de la actitud del filósofo hacia ésta. Smith llama la atención sobre cómo la filosofía natural es una práctica discursiva que ofrece razones para la adopción de una teoría ("Of the External Senses”, 12, 137; véase también Wightman, 1975: 61. Para la importancia en general de la persuasión en el pensamiento de Smith, véase Fleischacker, 2004: 92-94). Esto refleja cómo trata Smith la deliberación moral de nuestro Espectador Imparcial cuando, digamos, intentamos actuar con dominio de nosotros mismos y corrección. Es éste el motivo por el cual a menudo lo representa como la "voz" de la "razón" (TSM III.3.4, 137). María Alejandra Carrasco (2002: 84-89) señala con agudeza que Smith distingue entre nuestros "sentimientos naturales" y nuestra disciplina cultivada de ellos. Ella ha argumentado que TSM puede ser interpretada, por consiguiente, a pesar del lenguaje de los sentimientos y su oposición al racionalismo en la ética, como un sistema de la razón práctica (véase también el importante análisis de Montes, 2004: capítulos 2-4). Entre estas razones al interior de la filosofía natural, Smith identifica la simplicidad, la claridad, la comprensibilidad, la falta de competidores razonables y la descripción del fenómeno ("Of the External Senses”, 18, 140; “Astronomy” IV.15, 63-64). Smith a menudo adopta una posición realista. Por ejemplo, describe la adopción de las ideas copernicanas en términos realistas (“Astronomy” IV.35, 76-77). Destaca la capacidad de Newton de calcular los pesos y las densidades del sol y los planetas como merecedora de especial elogio (“Astronomy” IV. 75, 103). Se impresiona ante la sobrecogedora predicción de Newton de que una atracción mutua entre Júpiter y Saturno sería suficientemente fuerte como para perturbar sus órbitas cuando se aproximan a una conjunción (“Astronomy” IV.68, 99).

En la filosofía natural, según Smith, la aceptación de una teoría no obedece meramente a las invocaciones arbitrarias de las pasiones y los sentimientos (para una conclusión similar pero con un argumento diferente, véase Skinner, 1996: 41). La filosofía natural es una conversación permanente con las invocaciones a las opiniones intelectuales de los participantes (véase Fleischacker, 1999, sobre el importante papel que juega la opinión en Smith). No hay inconsistencia en considerar la teoría científica reinante

${ }^{11}$ Lauren Brubacker me hizo notar la importancia de este tema para Smith; véase Smith, carta No 40 a sir Gilbert Elliot (Corr. 49), véase Schliesser (2003). 
“como exacta o muy cercana a la verdad”, como escribe Newton en su cuarta regla del razonamiento, mientras se reafirma una teoría histórica y psicológicamente sensible sobre el desarrollo y la aceptación de las teorías científicas.

Smith siente un temor reverente por el alcance y el éxito predictivo de la teoría de Newton: bien fundada, físicamente plausible, hermosa, consistente, empíricamente adecuada y coherente (TSM III.2.20-22, 124-125). Pero la exposición de Newton no es necesariamente la última palabra; de acuerdo con la psicología de Smith, informada por sus investigaciones históricas, una vez que la gente se ha acostumbrado a la teoría de Newton, siempre existirá la posibilidad de que un investigador suficientemente avezado encuentre imperfecciones o irregularidades en sus principios estructurales, o que la ambición inquisidora y la vanidad de las personas las lleve a descubrir nuevos fenómenos (véase también Cropsey, 1957: 46). No requiere ser un sistema acabado con principios inalterables (como prometiera Descartes) sino un paso importante en un proyecto de investigación ya en marcha (véase la discusión de Smith de las “nociones imperfectas” en el "sistema del universo" de Newton en "Of the External Senses”, 12, 137). Los puntos de vista de Smith son muy newtonianos. En sus Principia, Newton expresó la esperanza de que "los principios aquí establecidos proyectarán alguna luz sobre este modo de filosofar o sobre algún otro más verdadero" (del "Prefacio del Autor para el Lector”, cursivas agregadas; véase Montes, 2006). Esto, junto con el hecho de que se puedan realizar nuevas o mejores observaciones, posiblemente apoyadas en avances tecnológicos ${ }^{12}$, da a entender que el “imperio de Newton” no necesariamente durará para siempre: habrá nuevos motivos para asombrarse.

A primera vista parecería, entonces, que Smith concuerda con Aristóteles en que la filosofía nace del asombro y termina en dogmatismo ${ }^{13}$. Smith sugiere que Aristóteles logra asir uno de los objetivos principales de la indagación de los filósofos: desean tener una mente tranquila. Smith enseña que los verdaderos filósofos descubrirán que ese objetivo es escurridizo; la naturaleza abierta y sin fin de la investigación científica significa

${ }^{12}$ Smith no menciona la posible importancia de la tecnología como un motor de cambio en "Astronomy”. Sin embargo, su afirmación de que el sistema de Eudoxo de las esferas concéntricas podría "haber resistido el examen de todas las épocas y haber salido triunfante hasta la remota posteridad" si no hubiera habido "otros cuerpos posibles de descubrir en el cielo" (IV.4.56), está basada en el hecho de que se hicieron visibles después de la invención del telescopio; esto además constituye una prueba adicional de su postura realista frente a los descubrimientos de la ciencia.

${ }^{13}$ Los editores de "Astronomy” apuntan al Theaetetus de Platón (155D) y a la Metafísica de Aristóteles, A (982b11-24). 
que toda teoría puede ser el inicio de una nueva investigación. La filosofía es una empresa abierta. Smith concuerda con Platón (Stein, 1988; por publicarse; sobre el platonismo en Smith, véanse Griswold, 1999, y Schliesser, 2003). La filosofía nace del asombro, profundiza nuestra comprensión y termina, no en la llamada “desesperanza de Hume” (Quine, 1969), sino en el asombro.

Vida común y filosofía

Smith destaca cuán lejos del sentido común pueden estar los contenidos de teorías científicas altamente exitosas: la hipótesis de Copérnico plantea que la Tierra y los planetas viajan "con una rapidez que casi excede toda comprensión humana" ("Of the External Senses”, 12, 137). Smith diferencia la manera en que distintos subgrupos de los doctos y del vulgo pueden reaccionar frente a las teorías (“Astronomy” IV. 36, 77). Smith concuerda en que es posible que las teorías científicas puedan llegar a ser ampliamente aceptadas, pero también tiene claro que los prejuicios de la vida común y corriente pueden impedir que teorías cada vez mejores logren aceptación, incluso entre los doctos.

Es más, el texto de "Astronomy" muestra que las normas de aceptación de una teoría en la comunidad de astrónomos pueden evolucionar y diferir de aquellas del público general; la coherencia, la capacidad de predicción (etc.) son factores, pero en el transcurso de sucesivas "revoluciones" de los sistemas esa lista puede extenderse. Incluso antes de su discusión sobre Copérnico, Smith muestra que los criterios para la aceptación de las teorías pueden cambiar. Una de las innovaciones en el campo de la astronomía es la demanda de explicaciones físicas de un fenómeno. Por ejemplo, Regiomantus y Purbach intentaron combinar la física de Aristóteles con la astronomía de Tolomeo (“Astronomy” IV.25-26, 69-71); lo mismo ocurrió cuando Newton ofreció una "demostración física” más allá de meras consideraciones estéticas (“Astronomy” IV.67, 97-98).

Sencillez, claridad y comprensibilidad, falta de competidores razonables y una debida presentación del fenómeno no agotan las razones para la aceptación de una teoría. En su “Astronomy”, Smith escribe:

Pues, aunque el fin de la filosofía sea mitigar ese asombro incoado tanto por los fenómenos inusuales como por aquellos aparentemente inconexos de la naturaleza, jamás alcanza ella mayor triunfo que cuando al relacionar entre sí a unos pocos objetos - tal vez en sí mismos insignificantes- crea, 
si se me permite decirlo de este modo, otra constitución de las cosas, más fácil de entender pero también más nueva, más contraria a la opinión y a las expectativas comunes, que cualquiera de esos fenómenos en sí (IV.33, 75).

Smith afirma así que el sello de una teoría exitosa es que ella sea inesperada, incluso sorprendente (véanse también los comentarios sobre la Historia de los Insectos de Reamur en su "A Letter to the Authors of the Edinburgh Review”, en EPS, 249). Mientras Hume había reprobado la codiciosa suscripción por parte de los filósofos de aquellas teorías que tienen “el aire de la paradoja”, y que de ese modo se distancian de los "juicios imparciales de la especie humana” (Treatise, 1.2.1.1), Smith no critica esos "triunfos". Está consciente de que cuando uno se topa con un sistema hermoso y magnífico, como aquel de Newton en sus días, incluso "los más escépticos no pueden evitar sentir" que sus principios poseen un "grado de firmeza y solidez" que parece un sin sentido buscar otro sistema ("Astronomy”, IV.76, 105). Aun así, semejante teoría, casi “otra constitución de las cosas”, con toda probabilidad creará una sensación de asombro y sorpresa que puede inducir a una reflexión acerca de sus fundamentos metafísicos o conceptuales y tal vez incentivar el desarrollo de nuevas teorías.

Sin embargo, para Smith, los criterios satisfactorios de evaluación adoptados por una comunidad de investigadores del presente o del futuro (cf. TSM III.2.20-22, 124-125) pueden suministrar razones públicas para rechazar los supuestos de la vida cotidiana. Por contraste, al discutir los méritos relativos de las teorías morales, Smith afirma que el experto puede rechazar el sentido común, pero el costo (en términos de persecuciones, escepticismo, rechazo, sátira, etc.) tal vez sea elevado: "El autor que nombrase como causa de cualquier sentimiento natural un principio que no tuviese ni relación con éste ni se pareciera a cualquier otro principio que guardara alguna relación con él, parecerá absurdo y ridículo aun al lector menos juicioso y experimentado” (TSM VII.ii.4.14, 314-315). El contexto sugiere, no obstante, que Smith es capaz de imaginar que un lector juicioso y experimentado podría concebir una explicación de la conducta humana en términos que resulten nada de familiares para la gente, pero esa explicación tendría una recepción hostil. Si bien las teorías de la filosofía natural pueden crear "otra constitución de las cosas [...] contraria a la opinión común" (“Astronomy” IV.33, 75), esto no es del caso en la filosofía moral. Una explicación respecto a la vida moral planteada en términos familiares puede lograr apoyo en la medida en que tenga algo de verdad. Es ésta la razón de que Smith a menudo suena como un así llamado "filósofo del sentido co- 
mún” cuando trata temas de filosofía moral ( $R N$ V.f.26, 769; véase Fleischacker, 2004: 22).

De modo que, en la perspectiva de Smith, aquello que he llamado el Problema Socrático puede surgir tanto en la filosofía natural como en la moral. Sin embargo, mientras la filosofía moral debe hacer concesiones a la sensibilidad de la vida común, la filosofía natural puede triunfar oponiéndose a ella. Claro que el conflicto entre la opinión popular y los astrónomos en torno a la hipótesis de Copérnico es, como lo demuestra el juicio contra Galileo, algo que no está siempre exento de peligros. Sin embargo, una vez que realmente se entienden los argumentos y la fuerza probatoria de la teoría de Newton (esto es, experimentar el mundo a través de ella), también ella debe sentirse como verdadera, (casi) "probada" (recuérdese TSM III.2.18, 123). Ésta es la razón por la que Smith puede hablar de acontecimientos empíricos que confirman la teoría de Newton (“Astronomy” IV.72, 101). Se puede volver parte del sentido común aun cuando Smith piense que el sentido común es bastante escaso. En efecto, si el sentido común fuese más común, un número mayor de personas sería capaz de evitar que su vanidad se transformase en el fundamento de diversos vicios (TSM III.2.4, 115). Desde el punto de vista teórico, Newton ha convertido a la gravedad en un "principio de conexión familiar” (“Astronomy” IV. 76, 105). Para Smith, incluso el sentido común y su "prejuicio natural" ("Astronomy" IV.37-38, 77 sig. y "Ancient Physics”, 10, 116) pueden ser corregidos mediante descubrimientos de la filosofía natural (cf. TSM III.3.2, 135 y, para una visión distinta, VII.iii.intro.3, 315). En su calidad de juez informado, Smith no puede evitar adoptar el esquema de Newton cuando evalúa los dichos de generaciones anteriores de astrónomos y filósofos, especialmente aquellos del siglo diecisiete (p. ej., el tratamiento de los vórtices de Descartes en TSM VII.ii.4.14, 313, o la reticencia de Descartes para entregar una descripción útil y sistemática acerca de cómo las observaciones empíricas pueden desviarse de las predicciones, “Astronomy” IV.66, 97). En el mismo pasaje, Smith critica los estándares de Descartes que eran ampliamente aceptados en el siglo diecisiete, incluso por Newton antes de escribir Principia (aunque no por Kepler). En efecto, Newton demostró que no se puede descansar en los criterios de Descartes.

Sin embargo, Smith no adopta de modo acrítico las posiciones de Newton. En su “Astronomy” IV.58, 90-91, critica a Newton por considerar lo que él (Smith) piensa es un mal argumento. Y en su "Of the External Senses”, 12, 137, Smith adopta tácitamente el marco teórico de Newton al hablar de "masas en movimiento" cuando hace una distinción entre aquellos saberes de la filosofía "a los que es escasamente posible rehusar nuestro con- 
sentimiento" y aquellas "nociones imperfectas" en el "sistema del universo" de Newton. En "Astronomy” IV.58, 90-91, Smith acepta que Newton ha entregado un nuevo y mejor conjunto de criterios, a pesar de que el propio Newton seguía dispuesto a emplear argumentos que apelaban al conjunto más antiguo de normas. En "Astronomy”, Smith adopta tácitamente la posición del Espectador Imparcial al discutir el impacto de Copérnico. Acude a criterios que Newton introdujo en la práctica del teorizar sobre la astronomía, criterios que no habían sido aceptados por anteriores generaciones de astrónomos.

De modo que el punto de vista teórico envuelve una disposición a ser persuadido por las razones y las evidencias que apoyan a las teorías de punta en la filosofía natural. Smith no intenta restringir o reinterpretar la teoría de Newton. Pero esto no significa que deba ser acrítico en su aceptación. Precisamente a través de una reflexión profunda y de la adopción de nuevas normas implícitas en el esquema de Newton, Smith puede ofrecer una crítica responsable y sugerir una revisión desde adentro o a la luz de la idea de perfección. Si bien la filosofía no puede gobernar a la ciencia, el naturalismo sofisticado no tiene por qué ser el fin de la reflexión seria. Es más, la filosofía de Smith enseña al investigador serio que existe una dimensión política en los orígenes y la recepción de las filosofías natural y moral.

\section{Política y filosofía}

En las primeras páginas de $R N$, Smith establece una distinción entre las opiniones de los "hombres de saber" y las de los "príncipes" ( $R N$, Introducción, 8, 11). De los últimos se dice que influyen sobre la "conducta pública”, mientras que los primeros probablemente influyen en la opinión pública o las visiones de los príncipes/estadistas. Las teorías no sólo intentan explicar y predecir el comportamiento económico, sino que también influyen en él, deliberadamente o sin intención, a través de las acciones de los gobernantes. De ahí que corren el riesgo de convertirse, por ejemplo, en profecías autocumplidas. Smith también podría estar apuntando a un contraste entre las opiniones de los "hombres de saber" y la conducta pública de los "príncipes".

Las teorías de la economía política pueden haberse originado en los "intereses privados y los prejuicios de determinado orden" de los individuos, aunque Smith, como siempre, es cuidadoso de formularlo de tal modo (emplea un "tal vez") de permitir también otras fuentes de motivación. Ade- 
más, en el contexto, Smith parece dar a entender que una vez que esas teorías están en el aire, pueden ser formuladas y propuestas con miras al "bienestar general de la sociedad” ( $R N$, Introducción, 8,11$)$.

En efecto, sería adecuado (proper) para ambos, "hombres de saber" y “príncipes”, tener este bienestar general en mente. Pues “[l]a más sublime especulación del filósofo contemplativo puede apenas compensar el descuido del más nimio de los deberes activos” (TSM VI.2.3.6, 237). Al contrario de aquellos que leen esto como un rechazo de Smith a la vida teórica (Cropsey, Griswold), yo lo entiendo como un mandato para los filósofos, en el sentido de no ignorar sus obligaciones morales ni rechazar de plano la vida teórica. En contraste con el "hombre doctrinario" (man of system), quien "se da ínfulas de muy sabio" (TSM VI.ii.2.16, 233), Smith escribe en forma aprobatoria acerca del "hombre cuyo espíritu público se ve impulsado exclusivamente por la humanidad y por la benevolencia” (TSM VI.ii.2.16, 233; Haakonsen, 1981). Dada la división del trabajo, no todos los filósofos calzarán en ese modelo: "sus grandes capacidades, si bien honorables para ellos mismos, podrían aportar muy poco al buen gobierno o a la felicidad de su sociedad" ( $R N$ V.i.f.51, 783).

También es una buena cosa que el filósofo propiamente tal (proper philosopher) se vea motivado por este bienestar general (Schliesser, 2003). Pues, según Smith, la sociedad moderna se compone de tres clases principales: los terratenientes, los trabajadores y los comerciantes ( $R N$ I.vi.17-19, 69-70; I.xi.p.7, 265). Salvo en las nuevas colonias, existe un conflicto inherente por los recursos entre los trabajadores asalariados y los comerciantes que buscan las utilidades (I.viii.11, 83; I.xi.p.8-10, 265-267). Desafortunadamente los dos "órdenes" de la sociedad cuyos intereses privados están "estricta e inseparablemente relacionados con el interés general de la sociedad", esto es, los terratenientes y los asalariados, son habitualmente (en el caso de los primeros), si no siempre (en el caso de los segundos), incapaces de "prever y comprender las consecuencias de cualquier regulación pública” (I.xi.p.8.-9, 265-266). Debido a ese vacío, las clases dedicadas al comercio llegan a dominar el proceso político para volverlo en su favor (p. ej. IV.iii.c.9, 493; I.x.c.61, 157-158). Se espera que el filósofo político "humano y benevolente” ¡salve a la sociedad de los mezquinos intereses de la clase que percibe las utilidades! Lo que se requiere es "una visión amplia del bien público” (IV.ii.44, 472). La adopción de esa visión amplia se adecua a los filósofos, quienes, a fin de cuentas, "observan todo".

La actividad del propio Smith como defensor político de la reforma de las instituciones (Rosenberg, 1960; Fleischacker, 2004: 242-246; Schlies- 
ser, 2005b) y educador de príncipes ${ }^{14}$ no sólo es comprensible sino también necesaria a la luz de la psicología moral implícita en $R N$. La existencia de $R N$ como una obra de filosofía política al servicio de los trabajadores pobres presupone un compromiso con un cierto tipo de benevolencia y humanidad. Por lo demás, cuando en nuestras relaciones comerciales nos dirigimos, digamos, a "carniceros, cerveceros o panaderos", no apelamos a su "humanidad sino que a su autoestima y nunca les hablamos de nuestras propias necesidades sino de sus ventajas" (I.ii.2, 27, aun cuando los pordioseros sí dependen en alto grado de la "benevolencia"), y al momento de diseñar y evaluar nuestras instituciones sociales y políticas apelamos a la "equidad" ( $R N$ I.viii.36, 96, V.ii.k.45, 888-889 y V.ii.k.55, 893), a la "humanidad” y a la "razonabilidad” (p. ej. $R N$ V.ii.e.6, 842; V.ii.e.19, 846; I.viii.36, 96; I.viii.44, 100, etc. Cf. la indignación de Smith ante la "insensatez e injusticia" de los colonizadores europeos en IV.vii.b.59, 588).

Dar consejo teórico a los príncipes y legisladores sobre las instituciones de la sociedad no agota el papel de la filosofía. Smith sostiene que el legislador sabio debe crear y poner en práctica variados incentivos para estimular la educación obligatoria de los jóvenes en filosofía (V.i.9.14, 796 y V.i.f.50-56, 781-786). Presumiblemente esto enseñaría a los futuros ciudadanos los rudimentos de las matemáticas y les daría una visión ordenada de la naturaleza. En vista de las exigencias epistémicas para evaluar lo correcto (propriety) (TSM I.i.3, 16-19; véase Forman-Barzilai, 2006), esto bien podría ser requerido para el adecuado funcionamiento de la moral. Si bien Smith estima que ese tipo de educación daría una genuina estabilidad al gobierno (V.f.61, 788), también recomienda "diversiones” públicas (p. ej. "pintura, poesía, música, danza” y "toda suerte de representaciones y exhibiciones dramáticas") para "entretención” de las personas y para hacer de los fanáticos políticos y religiosos objeto del "ridículo" ( $R N$ V.i.g.15, 796-797). De modo que para Smith la filosofía puede jugar algún papel en el proyecto de la Ilustración contra el fervor religioso (Schliesser, 2003) y en apoyo del orden público. Pero Smith no es optimista al respecto porque está consciente de que la "moral privada y pública de los romanos" era superior a aquella de las ciudades-estado griegas, tan ricas en filosofía, con su educación musical” ( $R N$ V.i.f.39-40, 776-777; Smith está aquí especialmente preocupado por los peligros del fanatismo y del sectarismo).

14 También Smith practica esto; se sabe que en la década de 1760 discutió materias políticas (especialmente relacionadas con las colonias en América) así como económicas con lord Shelburne, Secretario de Estado británico; véase Rae (1895: capítulo XV). 
Podría pensarse que el Problema Socrático se resuelve cuando la sociedad observa que la filosofía sirve a sus necesidades y se subordina a los objetivos de la sociedad. Sería extraño, sin embargo, atribuir esa posición a Smith, ya que postula lo que él describe como una actitud retórica contra aquellos que menosprecian a la filosofía. En la siguiente sección argumento que, para Smith, la preocupación por el bienestar general de la sociedad se justifica, al menos en parte, porque sin intención alguna sirve a las necesidades de la filosofía. Esto queda claro a la luz de la respuesta de Smith a las críticas de Rousseau respecto a la valía de la sociedad comercial.

\section{La respuesta de Smith a Rousseau}

La primera publicación de Smith (1755-1756), "Letter to the Authors of the Edinburgh Review" (EPS, 242-254), es una revisión de los logros intelectuales europeos, especialmente en materia de filosofía natural, con particular énfasis en los diferentes estilos nacionales (véase Lomonaco, 2002, para una importante introducción a este texto). Pero el último tercio de la obra está dedicado al Segundo Discurso de Rousseau — por ese entonces recientemente publicado—. Smith elogia la elocuencia de Rousseau, pero se abstiene de realizar un análisis de sus argumentos, porque dice que es imposible respecto de un libro "que contiene casi únicamente retórica y descripciones" $(12,251)^{15}$.

En la "Letters to the Authors...", Smith incluye traducciones de tres largos pasajes de la obra de Rousseau (13-15, 251-254). En el primero de estos pasajes, Rousseau discute la "saludable, humana y feliz" condición de los hombres en sus "rústicas moradas". Luego prosigue Rousseau describiendo cómo a partir del momento en que fue introducida la división del trabajo y cuando una persona pudo apreciar la ventaja de tener provisiones para dos (o más) personas, “desapareció la igualdad, se introdujo la propie-

\footnotetext{
${ }^{15}$ No está claro si acaso Rousseau tuvo noticia de los comentarios de Smith. En sus Confesiones VIII, Rousseau escribe acerca de la recepción del Segundo Discurso, que "en toda Europa halló tan sólo unos pocos lectores que lo comprendieron y de aquellos nadie deseaba comentarlo” (OC I, 388). Berry (1989, 1992) y Pack (2000) entregan útiles análisis introductorios sobre la relación de Smith con Rousseau. Aquí me ocupo en gran medida de cómo pudo Smith haber entendido a Rousseau, aunque ocasionalmente ofrezco una interpretación diferente de Rousseau. Al preparar este trabajo, me beneficié de la reseña (para entonces aún no publicada) que hace Berry (2004) de una obra de Force (2003) y del muy perspicaz trabajo de Hanley (sin publicar) sobre la respuesta de Smith a Rousseau. Mi análisis no puede hacer justicia a los complejos y provocativos argumentos de Force.
} 
dad, se hizo necesario el trabajo [...] y pronto se vio a la esclavitud y la miseria germinar y crecer con las mieses” (13, 251-252; cf. Segundo Discurso, Parte II.19, OC III, 171. Pack, 2000:52 n.25 señala que Rousseau está más preocupado de los efectos físicos de la división del trabajo mientras Smith se preocupa más de los psicológicos; $R N$ V.i.f.50, 781).

En el segundo pasaje, Rousseau describe cómo después del desarrollo de la propiedad y de la desigualdad y el comienzo de una actividad comercial más generalizada, basta con que los hombres parezcan beneficiosos unos a otros. Las nuevas necesidades estimuladas por una "insaciable ambición" y una secreta envidia hacen que las personas "repetidamente usen caretas unas frente a otras". Mientras en el estado de naturaleza el hombre es "libre", el hombre civilizado es un "esclavo" de la naturaleza y se "sitúa por sobre todas sus criaturas semejantes". Rousseau insiste en la falsedad de la vida comercial: "Ser y parecer ser se volvieron dos cosas muy diferentes” (14, 252-253; Segundo Discurso, Parte II.27, OC III, 174175).

En el tercero y más largo pasaje traducido, Rousseau contrasta la "libertad y tranquilidad", incluso más allá de la "ataraxia de los estoicos", del salvaje autosuficiente que "vive en sí mismo" en estado de naturaleza, con los incesantes y dañinos esfuerzos de las "ocupaciones" del "ciudadano" en sociedad, que en forma degradante a su vez se dedica a adular a sus superiores. El hombre civilizado desea "poder y reputación” porque "vive en la opinión de los otros", pero sólo acaba con "un exterior engañoso y frívolo". La sociedad comercial alienta el descubrimiento y la importancia permanente de "ser vano" $(15,253)$. La vida comercial es, entonces, incompatible con la verdadera virtud, la sabiduría y la felicidad (15, 254; Segundo Discurso, Parte II.57, OC III, 192-193. Véase Dent, 1988: 55 y sig. para una discusión).

Smith deja sin explicar por qué elige estos tres pasajes en particular. Pero con el beneficio del tiempo podemos observar que los tres se hacen eco de temas que Smith elabora más adelante en sus obras. Está claro, sin embargo, que Smith considera que la descripción que hace Rousseau de la vida en estado natural es unilateral: "El señor Rousseau, intentando mostrar la vida salvaje como la más feliz de todas, presenta sólo la cara indolente del asunto". De acuerdo con Smith, Rousseau deja fuera "las más peligrosas y desmesuradas aventuras” (12, 251; la principal crítica de Smith contra otros filósofos morales es precisamente que sus sistemas también "derivan de una visión parcial e imperfecta de la naturaleza”, TSM VI.i.1, 265; véase Schliesser, 2005a). Si bien en términos estrictos esto puede ser correcto, la crítica de Smith es un poco injusta. Smith ignora que para Rousseau son los peligros y obstáculos a que el hombre está expuesto en el estado natural los 
que inician la cadena de eventos que no sólo conducen a éste a descubrir los beneficios de la tecnología y el confort de la vestimenta, sino que también generan las circunstancias que por primera vez suscitan el orgullo en el hombre (Segundo Discurso, Parte II. 3-6, OC III, 165-166). Hay más de Hobbes en Rousseau de lo que Smith reconoce.

Sin embargo, Smith elogia las dotes retóricas de Rousseau: "Aunque elaborada y afectadamente elegante ([la prosa de Rousseau posee] siempre suficiente nervio y en ocasiones incluso es sublime y patética” $(12,251)^{16}$. En otra parte, por contraste, la "elocuencia" de Mandeville es descrita como "vívida y llena de humor, aunque ordinaria y rústica” (TSM, VII.ii.4.6, 308; también VII.ii.4.11, 312: "La ingeniosa sofisticación del razonamiento [de Mandeville] ... está cubierta por la ambigüedad del lenguaje”). Como una manera de incluir la idea del buen salvaje al estilo de Rousseau, Smith produce su propio resumen retórico: "Es con la ayuda de este estilo, junto con un poco de química filosófica, que los principios e ideas del libertino Mandeville parecen adquirir la pureza y exaltación de la moral de Platón, y ser sólo el genuino espíritu republicano llevado un tanto lejos" ("Letters to the Authors of the Edinburgh Review", 12. 251; véase Livingston 1998 sobre la "química de la filosofía", aunque éste no menciona a Smith). Smith denuncia que Rousseau no es sólo algo extremista en sus convicciones políticas (nótese ese “jun tanto lejos”!) sino que, a pesar de las apariencias en contra ("parecen”), Rousseau está en el fondo en el mismo barco que el "libertino y escandaloso Mandeville" —un intento ad hominem de condenar a Rousseau por ser culpable de asociación-. En un giro irónico, Smith ataca las falsas apariencias de Rousseau. Después de todo para Rousseau "desenmascarar” era una actividad importante (Starobinski, 1988; véase también el segundo pasaje que Smith traduce del Segundo Discurso en el "Letters to the Authors ...”, 14, 253) ${ }^{17}$.

El diagnóstico de Smith dice que Rousseau y Mandeville comparten cuatro importantes características. Primero, en su reacción contra Hobbes, quien gozaba de popularidad entre pensadores como Grotius, Pufendorf y Hutcheson, tanto Rousseau como Mandeville suponen que "no hay en el hombre un instinto tan poderoso que necesariamente lo conduzca a buscar

${ }^{16}$ Smith emplea a todas luces el término "patético" en el sentido tradicional de "excitar las pasiones o los afectos: mover, impulsar, afectar", mientras por "nervosidad" probablemente entienda algo cercano a "vigoroso, poderoso, enérgico" (Oxford English Dictionary).

${ }^{17}$ Durante la controversia entre Rousseau y Hume, Smith urgió a Hume a no intentar “desenmascarar” a Rousseau "ante el público", insinuando que correría el riesgo de "perturbar para siempre la tranquilidad de su vida" (Correspondence of Adam Smith, carta $\left.\mathrm{N}^{\circ} 93,113.\right)$ 
la sociedad por el bien en sí de ésta”. Segundo, ellos suponen “el mismo progreso lento y gradual desarrollo de los talentos, hábitos y artes que hacen que los hombres puedan convivir en sociedad, y ambos [lo] describen [...] del mismo modo" (sobre Mandeville y las explicaciones del orden no intencional, véase Heath 1998.) Es más, de acuerdo con ambos, “aquellas leyes de la justicia que mantienen la actual desigualdad en la especie humana fueron en su origen invenciones de los astutos y los poderosos para conservar o adquirir una superioridad injusta y contraria a la naturaleza por sobre el resto de sus iguales”. Finalmente, concuerdan en que la compasión “es propia de los salvajes y de los más disolutos entre los vulgares, en un grado mayor de perfección que en aquellos de modales más refinados y compuestos” (11, 250-1).

Sin embargo, Smith no pasa por alto sus diferencias; reconoce que Rousseau es un feroz crítico de Mandeville. Smith destaca la importancia que tiene para Rousseau la compasión en la producción de la virtud. Esto es perspicaz, dada la importancia que la compasión adquirirá en obras posteriores de Rousseau (Dent, 1988: cap. 4). Sin embargo, el texto de la "Letters to the Authors of the Edinburgh Review" no deja en claro dónde exactamente se sitúa $S_{m i t h}{ }^{18}$. Desafortunadamente ésta sería la última vez que Smith comenta por escrito a Rousseau; en las "Considerations Concerning the First Formations of Languages" discute solamente los puntos de vista de Rousseau sobre el lenguaje (2, 205 de $L R B L$; véanse también Lección 3 de LRBL; Pack, 2000: 48; Otteson, 2002: 263-265).

No soy el primero en advertir importantes similitudes entre las posturas de Smith y Rousseau (Force, 2003). Smith señala que tanto Mandeville como Rousseau adscriben el origen de las leyes de la justicia a las "invenciones de los astutos y de los poderosos" ("Letters to the Authors of the Edinburgh Review”, 11, 251). La descripción que hace Smith del origen de la justicia en $R N$ deja en claro que también él piensa que el "gobierno civil, en tanto es instituido para la seguridad de la propiedad, es en realidad instituido para la defensa de los ricos contra los pobres, o por aquellos que tienen alguna propiedad contra quienes no poseen ninguna” ( $R N$ V.i.b.12,

${ }^{18}$ Pack (2000: 46-47 y 55) piensa que el uso que hace Smith del término "simpatía” deriva del uso que hace Rousseau de la palabra compasión; Pack cita a TSM I.i.1.5, 10. Yo entiendo este pasaje como una advertencia de no confundir compasión y simpatía. Si bien hay algo interesante en la sugerencia de Pack, él pasa por alto sin embargo que para Smith la simpatía no es meramente una empatía, como lo es la compasión, sino que también una actividad imaginativa (I.i.1.10, 12). Berry (2004) nos ofrece la misma crítica de Force (2003), quien parece tener una versión más compleja de la posición de Pack. Para una importante discusión del empleo por Smith del término simpatía, véase Darwall (1998: 246-249), Montes (2004, capítulo 2) y Levy y Peart (por aparecer). 
715; V.i.b.3, 710; véanse Schliesser y Pack, por publicarse; Schliesser, 2005a). Smith también acepta que hay un desarrollo "gradual” de las civilizaciones (p. ej. I.x.g.19, 218) y concuerda con que el deseo de vivir en sociedad es resultado de la socialización (TSM III.i.2-6, 109-113).

Smith y Rousseau también están de acuerdo en que la riqueza por sí sola nunca conduce a una "verdadera satisfacción” (TSM IV.1.8, 181; cf. Segundo Discurso, Nota IX 3, OC III, 203). Rousseau y Smith están conscientes de que una vez cultivados y estimulados, nuestros deseos pueden tornarse ilimitados. A lo largo de TSM Smith insiste en que si bien preferimos ser ricos en orden a ser admirados (I.iii.2.1, 50 y sig.), la riqueza no conduce a la felicidad y que "la parte principal de la felicidad humana viene de la conciencia de ser amados” (I.ii.5.1, 41; en III.i.7, 113, Smith agrega que también deseamos sentir que merecemos ser amados). Rousseau no estaría en desacuerdo, pero insistiría en que la necesidad de ser amados solamente surge una vez que el hombre ha salido del estado natural; una vez en sociedad, él "no puede vivir sino en la opinión de otros" ("Letters to the Authors of the Edinburgh Review”, 15, 253; Segundo Discurso, Parte II. 57, OC III, 193). De modo que mientras Smith asevera: "qué puede añadirse a la felicidad de una persona que goza de buena salud, que está libre de deudas y tiene la conciencia tranquila” (TSM, I.iii.I.7, 45), Rousseau escribe, al hablar de un hombre en estado natural: “qué tipo de miseria” puede aquejar a "un ser libre, cuyo corazón está en paz y cuyo cuerpo goza de salud” (Segundo Discurso, Parte I.33, OC III, 152). La mención de las deudas deja en claro que Smith sólo habla del individuo tal como lo encontramos en una sociedad en la que a lo menos ya han sido desarrolladas algunas relaciones comerciales.

En una sociedad comercial es imposible la libertad genuina tal como la entiende Rousseau en su Segundo Discurso, es decir es imposible la independencia en la forma de "autosuficiencia". No debe sorprender, entonces, que Smith no haga mención de ella ${ }^{19}$. Contra el extremista énfasis "republicano" de la autosuficiencia en Rousseau, Smith sigue más bien la sugerencia de Hume de abogar por una forma distinta de "independencia”, una forma que resalte nuestra mutua interdependencia (Berry, 1989; Schliesser, 2003). Éste es el punto contextual más importante del tantas veces citado pasaje del mendigo/carnicero/panadero/cervecero en $R N$ I.ii.2, 25-27): "En la sociedad civilizada, [el hombre] está en todo momento necesitado de la cooperación y la asistencia de grandes multitudes”.

${ }^{19}$ Las visiones positivas de Rousseau acerca de qué es deseable y bueno para el hombre moderno no quedan claras en el Segundo Discurso. Desafortunadamente no disponemos de información fidedigna acerca de cómo reaccionó Smith frente al Emilio o al Contrato Social. 
Vemos entonces cómo a partir de sus primeros escritos Smith advierte que el cuestionamiento al valor de la sociedad comercial que hace Rousseau es retórico. Rousseau procede, en nombre de la libertad, a condenar la vida comercial porque fomenta falsedades y enmascaramientos, sugiriendo que habrá de preferirse la autosuficiencia por sobre aquello que podríamos llamar una "independencia interdependiente" que es presupuesta y alentada por la vida comercial. En este contexto cobra nueva importancia que Smith califique elogiosamente de "panegírico justo" ("Letters to the Authors ...”, 16, 254) la dedicatoria a la "República de Ginebra” del Segundo Tratado de Rousseau. Smith es suficientemente ambiguo como para dejar abierto si acaso el carácter justo del panegírico se debe al hecho de que Rousseau es un "buen ciudadano" (16, 254), indicando que él (Smith) cree que la expresión adecuada del patriotismo es una virtud importante (prudente) en un filósofo (a la luz del Problema Socrático), o bien que Smith suscribe aquí un republicanismo de estilo ginebrino. Ambos no son mutuamente excluyentes, por supuesto (cf. Pack, 2000: 44).

Siguiendo a Hume, la respuesta de Smith a Rousseau (y Mandeville) contempla su bien conocida defensa de la moralidad de la búsqueda del interés propio (TSM VII.2.4.12, 312; véase Otteson, 2002). Pero también contempla un reconocimiento de la naturaleza política que tiene la existencia de los mercados en la sociedad moderna. (Con esto no se pretende negar que Smith piensa que algunas permutas e intercambios puedan realizarse en el estado natural; $R N$ I.ii.1, 25.) La insistencia de Smith en el pasaje del carnicero, cervecero y panadero de que ni siquiera los mendigos dependen primordialmente de la "benevolencia" de sus "conciudadanos" ( $R N$ I.ii.2, 27; cursivas del autor) no es una frase inocente. Es evidente que el mendigo y el comerciante no se relacionan entre sí (Fleischaker, 2004: 91) únicamente como mercaderes interdependientes que persiguen su interés propio ( $R N$ I.iv.1, 37; Berry 1989: 114 y sig.) o consumidores (RN IV.viii.49, 660). Hay también una dimensión política. Nuestras formas modernas de intercambio se efectúan en un contexto político, como también lo sugiere la discusión sobre los impuestos: "Cada impuesto, sin embargo, es para la persona que lo paga una señal de libertad, no de esclavitud" ( $R N$ V.ii.b.3, 82). Nuestra libertad está ligada a nuestra pertenencia a una sociedad política.

La filosofía política moderada de Smith corrige el republicanismo extremista de Rousseau (recuérdese "Letters to the Authors of the Edinburgh Review”, 12, 251). Smith rechaza la libertad basada en la esclavitud de los antiguos, las virtudes de la autarquía, el agrarismo y el espíritu público de los ciudadanos. Para Smith, en cambio, todo lo que se requiere en este republicanismo moderno y moderado es un compromiso con la virtud negativa de la justicia (TSM II.ii.3-4, 86), junto con las "respetables virtudes de la 
industriosidad y de la frugalidad" (VI.iii.13, 242), sumadas a lo que Smith llama la virtud de la "prudencia inferior" (VI.ii.14, 216) y a una mayor representación (RN IV.vii.c.77-79, 624-626 y IV.vii.b.50-51, 584-585). (Véanse Fleischacker, 2004: 246-249 y, especialmente, Montes, 2003: 58-69). Claro que esto presupone que el filósofo con vocación de servicio público puede influir sobre el legislador en la creación de la estructura institucional correcta para el sistema de la "libertad natural” (Brubaker, Capítulo 8, más arriba). El libro V de $R N$ está dedicado a este proyecto (Rosenberg, 1960; Schliesser, 2005b).

Por supuesto que Smith está en profundo desacuerdo con las pretensiones de Rousseau en los pasajes de Segundo Discurso que él mismo tradujo en al menos otras tres formas. Primero: Rousseau piensa que la tranquilidad sólo se encuentra en el estado natural; el pensador francés sostiene el ideal de un hombre autosuficiente y auténtico (Rousseau no emplea el término "auténtico", pero en la traducción de Smith lo hemos visto criticar las "falsas y artificiales" apariencias del hombre civilizado). Smith afirma, sin embargo, que en la sociedad hay diversas formas de tranquilidad que pueden obtener los hombres prudentes, quienes mediante "continuos aunque pequeños ahorros" ven mejorada su situación (TSM VI.i.11-13, 215-216; para la tranquilidad como fuente de felicidad, p. ej. TSM III.3.30-33, 149-152; III5.6, 166; I.ii.3.7, 37), en especial los matemáticos y los filósofos naturales (III.2.20, 124 y sig.). Smith estima que los primeros pueden alcanzar la tranquilidad porque viven dentro de sus posibilidades y evitan las conmociones. Smith piensa que los hombres de teoría son tranquilos porque su éxito no depende de la "opinión pública”. No están retirados del mundo, pero pueden experimentar la satisfacción de saber que su éxito está en sí justificado. Claro que no todos los miembros de una sociedad pueden alcanzar la tranquilidad; en TSM, Smith habla del "vano esplendor de una ambición satisfecha” (VI.i.13, 216) que causa que los hombres eludan la tranquilidad, mientras que en $R N$ "la mezquina voracidad [...] de los comerciantes y fabricantes" es identificada como causa de tal fracaso (IV.iii.c.9, 493; cf. Mirowski, 1989: 161)20.

${ }^{20} \mathrm{Al}$ parecer Smith piensa que por naturaleza el telos del ser humano es el de un campesino. Él piensa que bajo condiciones políticamente estables la "independencia" está "realmente" disponible en la vida rural, pero la considera una forma primitiva de empleo aun cuando esté presente en fases posteriores ( $R N$ III:i.3, 378). Ciertas partes del Emilio pueden interpretarse como si Rousseau favoreciera el republicanismo rural. Es cierto que en $R N$ no hay ejemplos de pueblos que en realidad alcanzan la tranquilidad; eso podría tentarlo a uno a afirmar que TSM y $R N$ se contradicen respecto a este punto. Sin embargo, como muestran $R N$ III.i.3, 378, y IV.iii.c.9, 493, Smith sigue considerándola el objetivo de la vida y nada de lo que él dice sugiere que haya cambiado sus ideas respecto de aquellas ocupaciones que propiamente conducen a la tranquilidad. 
Segundo, Smith está en desacuerdo con Rousseau en cuanto a que la invención de la propiedad debe inevitablemente conducir a una (vasta) desigualdad; esto depende de la estructura institucional y de las políticas aplicadas ( $R N$ I.10). Para Smith, la mano invisible puede, en circunstancias adecuadas, ser una fuerza favorable para cierta equidad (al menos en TSM IV.i.10, 185). Smith está totalmente consciente de variados tipos de fracaso del mercado (Pack, 1991), pero piensa que el sistema de la "libertad natural" ( $R N$ IV.ix.51, 687, y I.x.c59, 157) será de gran ayuda para la humanidad, especialmente para los trabajadores pobres ${ }^{21}$.

Tercero, en el pasaje que conduce a la invocación de la mano invisible en TSM, Smith parece insinuar que la concepción rousseauniana de que la vida civilizada es un "despreciable y baladí [...] engaño" es errada; se trata sólo de una "luz abstracta y filosófica” (véase también TSM I.iii.3, 5253). Smith parece impugnar la tendencia de los filósofos a mirar despectivamente nuestras vidas corrientes, lo que coincide perfectamente con su visión de que los propios filósofos son también parte de la división del trabajo. Es más, en contra de Rousseau, Smith parece ponerse de lado del engaño de la naturaleza: "es bueno que la naturaleza se nos imponga de esa manera"22. El engaño de nuestra imaginación consiste en creer que "los placeres de la riqueza y de la magnificencia” son "algo excelso, hermoso y noble, cuya obtención bien vale todo el esfuerzo y desvelo que estamos tan dispuestos a dedicarles”. Muchos han visto en esta frase el apoyo de Smith a la sociedad comercial. Sin embargo, la postura de Smith es un tanto más complicada.

Veamos el siguiente fragmento del primero de los pasajes traducidos por Smith:

desde el instante en que un hombre tuvo la ocasión de ser asistido por otro, desde el momento que entendió que podría ser ventajoso para una sola persona tener provisiones para dos, desapareció la igualdad, se introdujo la propiedad, se hizo necesario el trabajo y los vastos bosques de la naturaleza fueron transformados en agradables praderas que deben regarse con el sudor del hombre, y pronto se vio la esclavitud y la miseria germinar y crecer con las mieses $(13,252)$.

${ }^{21}$ Malthus fue el primero en notarlo y hoy rápidamente se está convirtiendo en una visión indiscutida (Pack, 1991; Rothschild, 2002; Fleischacker, 2004). El Discurso sobre Economía Política de Rousseau es una fuente no explorada de las estrategias redistributivas de Smith.

${ }^{22}$ Pack (2000: 49-50) cita la Nota IX, OC III, 202 de Rousseau para sugerir que también Rousseau suscribe el engaño, aunque el pasaje expresa la afirmación contraria. 
Como destacan los editores de TSM, siguiendo una sugerencia de H. B. Acton, Smith se hace eco de esto:

\begin{abstract}
Nos deleitamos entonces con la belleza de las comodidades que reinan en los palacios y la economía de los poderosos; y admiramos cómo cada cosa está adaptada para promover su comodidad, impedir que necesiten algo, complacer sus deseos y divertir y festejar sus más frívolos deseos. Si consideramos la verdadera satisfacción que todas estas cosas pueden proporcionar, por sí solas y separadamente de la belleza del orden dispuesto para producirla, siempre nos parecerá en sumo grado despreciable y baladí. Pero rara vez la vemos bajo esta luz abstracta y filosófica. La confundimos naturalmente en nuestra imaginación con el orden, el movimiento regular y armonioso del sistema, la maquinaria o economía a través de la cuál se produce. Los placeres de la riqueza y de la magnificencia, considerados desde esta compleja perspectiva parecen algo excelso, hermoso y noble, cuya obtención bien vale todo el esfuerzo y desvelo que estamos tan dispuestos a dedicarles.

Y está bien que la naturaleza abuse de nosotros de este modo. Este engaño es lo que despierta y mantiene en permanente movimiento la laboriosidad en los seres humanos. Es este engaño el que los llamó primero a cultivar la tierra, a construir casas, a fundar ciudades y repúblicas, a inventar y mejorar todas las ciencias y las artes que ennoblecen y embellecen la vida humana, lo que ha cambiado enteramente la faz de la tierra, transformado los enmarañados bosques en agradables y fértiles praderas y convertido el océano inexplorado y yermo en una nueva fuente de subsistencia y en la gran vía de comunicación con las diferentes naciones de la tierra (TSM IV.1.9-10, 183-184).
\end{abstract}

Cito en extenso no sólo para mostrar que en estas líneas Smith pudo haberse hecho eco de unas pocas palabras de Rousseau (los bosques convertidos en praderas) precisamente antes de introducir la metáfora de la mano invisible en TSM (Rousseau incluso menciona una "mano invisible" en su propia Nota VI.5, OC III, 200, pero en un contexto en que su uso es muy diferente del que le da Smith a esa famosa frase.) En cierto importante sentido, Smith está de acuerdo con Rousseau en que desde cierta perspectiva de la historia la civilización es un "despreciable y miserable [...] engaño”, esto es, el producto de los vanos deseos de nuestra imaginación. Pero, de acuerdo con Smith, "esa luz abstracta y filosófica” no parece capaz de tentar a la mayoría de las personas cuando gozan de salud; es más proba- 
ble, en cambio, que se apodere de nosotros esa "irascible filosofía [...] de épocas de mala salud o de espíritu alicaído” (TSM IV.i.9, 183; en III.2.27, 127, Smith también emplea la frase "filósofos irascibles", refiriéndose probablemente a Mandeville).

Alguien con más de una mínima familiaridad con el Segundo Discurso puede verse sorprendido por el hecho de que en nombre de Smith yo atribuya a Rousseau un punto de vista "abstracto y filosófico". Después de todo, incluso en el Segundo Discurso Rousseau se coloca a menudo del lado de nuestras pasiones naturales en contra del razonamiento abstracto, simplista e incluso vanidoso (cf. $R N$ I.ii.4, 29) de los filósofos (p. ej. Parte I.37-38, OC III, 156-157, en que Rousseau discute a Mandeville, y Nota XVII, OC III, 220). Esos pasajes bien podrían leerse como si fuesen filosofía de Smith. En efecto, uno de estos episodios se presenta justo antes del tercer extenso pasaje que Smith cita del Segundo Discurso. Pero Rousseau prosigue diciendo que el "lector atento" comprenderá por qué la "sociedad ya no presenta a los ojos del hombre sabio nada más que un ensamblaje de hombres artificiales y pasiones artificiosas que son producto de todas esas nuevas relaciones y que carecen de un verdadero arraigo en la naturaleza” (Parte II.57, OC III, 192). No sería de extrañar, entonces, que Smith identificara a la irascible y abstracta luz filosófica, la visión de que la sociedad es un mero ensamblaje de hombres artificiales, con la posición de Rousseau ${ }^{23}$.

Smith opina que el rechazo de la mayoría de la gente a un punto de vista desapegado y abstracto es una buena cosa la mayor parte del tiempo. Según Smith, este rechazo es causado por el modo en que nuestra naturaleza permite que nuestra imaginación nos engañe: "despierta y mantiene en incesante movimiento la laboriosidad del hombre” (TSM IV.i.10, 183) ${ }^{24}$. Es éste el motivo de por qué originalmente sugerí que Smith está en desacuerdo con Rousseau.

Pero Smith habla desde un punto de vista en que el "engaño" de la naturaleza puede ser identificado y evaluado. No se trata ni de "filosofía irascible” ni de nuestro punto de vista común. Resulta difícil explicarse cómo la moralidad convencional podría producir este punto de vista moral, puesto que sugiere con tanta claridad que nuestros objetivos morales convencionales son un “engaño” de la “imaginación” (TSM IV.i.9-10, 183). Más

${ }^{23}$ Por supuesto que Smith jamás dice que tiene aquí en mente a Rousseau; tal vez sólo piensa en el estoicismo. En oposición a Brown (1994) y muchos otros comentaristas, acepto la posición de Rothschild (2002), Montes (2003) y Fleischacker (2004: 120) de que Smith es un crítico sutil del estoicismo, aunque me di cuenta de ello por primera vez en una conversación con Lauren Brubaker.

${ }^{24}$ Es mi impresión que para Rousseau la “voz de la naturaleza” jamás puede mentir. 
bien se trata del enfoque que he llamado el punto de vista teórico. Por cierto que Smith admite que es "raro" (TSM IV.i.9, 183) e impopular adoptar el punto de vista teórico: "El filósofo sólo es compañía para otro filósofo; el miembro de un club, para su pequeño círculo de amistades" (TSM I.ii.2.6, 34). Los filósofos buscan la amistad y la admiración de otros filósofos: "Podemos decir con Parménides que, mientras leía un discurso filosófico ante una asamblea pública en Atenas, observó que salvo Platón todos sus auditores se alejaban, pero igual prosiguió con su lección, ya que, como dijo, Platón era suficiente público para él” (VI.iii.31, 253).

Smith aprueba el engaño de la naturaleza ${ }^{25}$. Pues algunos de los logros no intencionados de la civilización, es decir las artes y las ciencias, “ennoblecen” nuestras vidas (IV.i.10, 183, véase también su defensa del lujo como causa del "refinamiento en las artes" en VII.ii.4.12, 313). Smith no confunde nuestros "deseos frívolos" (IV.i.9, 183) con los nobles. Es el engaño de la naturaleza lo que primeramente hace posibles las cosas nobles y más finas de la vida. ¡Nuestros deseos habitualmente frívolos y vanos posibilitan la creación de cosas más nobles! (No es el único engaño que Smith aprueba. Pack, 2000: 51, llama la atención sobre TSM I.i.1.13, 13, donde de un modo propio de Hobbes el miedo a la muerte es "el gran freno para la injusticia humana”. Véase también Cropsey 1957.) De manera que Smith no solamente piensa que Rousseau no entrega una visión lo suficientemente equilibrada de la vida del salvaje al omitir los peligros que encierra, sino que Smith también piensa que hay elementos de la civilización, las artes y las ciencias que se desarrollan al amparo de la ley, y todo un conjunto de instituciones sociales (incluyendo la división del trabajo, las universidades, los hombres en boga, etc.) que son dignas de ser defendidas desde un punto de vista teórico. Para nuestros fines inmediatos no es importante examinar en qué grado Rousseau rechazó este punto de vista teórico ${ }^{26}$.

${ }^{25}$ Podría pensarse que esto vuelve moralmente problemática la defensa que hace Smith de la vida comercial: podría parecer que la vida comercial se torna en un engañoso medio para favorecer los fines "elitistas" de unos pocos. Entre otras cosas, esto violaría la demanda de una igualdad de reconocimiento identificada en la teoría moral de Smith (véase Darwall, 2004, y Schliesser, 2005a). No puedo tratar esto aquí en forma adecuada, pero vale la pena destacar que el engaño no incluye a la vida comercial en general, sino que sólo a "los placeres de la riqueza y de la magnificencia [...] que aparecen como algo excelso, hermoso y noble”. La confusión en torno de qué es realmente excelso, hermoso y noble deja amplio espacio para una justificación de la actividad comercial común y corriente.

${ }^{26}$ En la Observation by Jean-Jacques Rousseau of Ginebra on the Answer made to his Discourse, que es una respuesta a las críticas del Primer Discurso, Rousseau escribió: "La ciencia es muy buena en sí, esto es obvio; y habría que haber perdido la sana razón para sostener lo contrario” (7, OC III, 36). 
Smith combate la retórica de Rousseau que parece rechazar no sólo la vida comercial sino también sus ennoblecedores subproductos. Smith da su aprobación a la vida comercial en cuanto medio para la filosofía (concebida en términos amplios). Desde luego, esto no obsta para que también dé su aprobación a la vida comercial por otros motivos (p. ej., por el papel que juega en la reducción de la pobreza, en la dignidad de los pobres o en la promoción de la seguridad nacional).

Hay una ironía en todo esto: pienso que la adopción por Smith del punto de vista teórico es una instancia en que la tranquilidad del filósofo no depende de la opinión pública general sino que de un público muy restringido (recuérdese el episodio de Parménides y Platón). Es el momento en que el filósofo se vuelve prácticamente autosuficiente. De modo que desde el punto de vista de la vida común, la filosofía es simplemente una más entre otras ocupaciones que la consecución de la "independencia interdependiente” permite y posibilita. Pero cuando el filósofo se las arregla para "observarlo todo" - ya sean los logros de un Newton o el funcionamiento de la sociedad— el filósofo se sentirá autosuficiente (cf. la descripción de cómo se alcanza la "independencia" en TSM III.2.20, 12).

La (rara) adopción de este punto de vista teórico por Smith ${ }^{27}$ muestra que la defensa del mercado y su relación con la vida no es en modo alguno directa. Smith sigue el ejemplo de Hume; la vida comercial se justifica porque permite la vida filosófica (véase también Schliesser, 2003). En términos estrictos, los filósofos "no necesitan hacer" algo, pero su interés propio los conduce hacia el espíritu público. Si el filósofo es prudente, la sociedad comercial resuelve el Problema Socrático. A veces Smith, el filósofo humano y benevolente, acepta el engaño de nuestra imaginación, enraizada como está en el habitual y "frívolo" interés propio ${ }^{28}$.

${ }^{27}$ Smith se queja del diccionario de Johnson porque no fue lo suficientemente teórico, y ofrece ejemplos de cómo un diccionario "suficientemente gramático" ("Review of Johnson's Dictionary”, 1,232-1233 en EPS) clasificaría y distinguiría diferentes palabras.

${ }^{28}$ Desde luego, este elitismo sumamente estrecho es compatible con muchas formas de igualdad política, normativa y económica, y mi argumento no atenta contra las afirmaciones de Fleischacker sobre Smith en estos aspectos. 


\section{BIBLIOGRAFÍA}

\section{a) Abreviaciones y referencias de las obras citadas de Adam Smith}

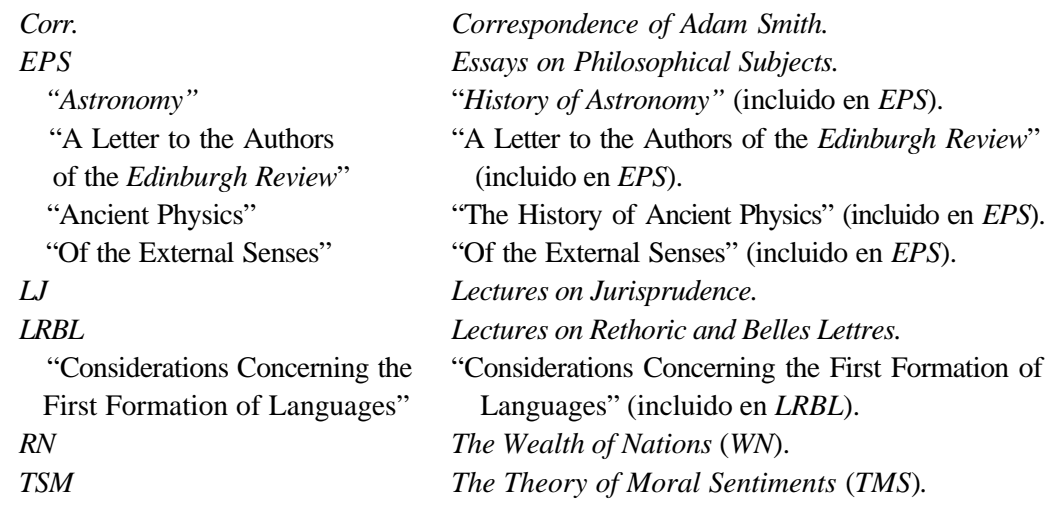

Las referencias siguen las divisiones, párrafo(s) y finalmente página(s) de las ediciones en inglés de Liberty Fund, que son reproducciones fotográficas de las publicadas por Oxford University Press, basadas a su vez en la edición emprendida por la Universidad de Glasgow:

(Corr.) Correspondence of Adam Smith. E. C. Mossner e I. S. Ross (eds.). Indianápolis: Liberty Fund, 1987 [Oxford University Press, 1977, 1987].

(EPS) Essays on Philosophical Subjects. W. P. D., Wightman y J. C. Bryce (eds.). Indianápolis: Liberty Fund, 1982 [Oxford University Press, 1980].

(LJ) Lectures on Jurisprudence. R. L. Meek, D. D. Raphael y P. G. Stein (eds.). Indianápolis: Liberty Fund, 1982 [Oxford University Press, 1978].

(LRBL) Lectures on Rethoric and Belles Lettres. J. C. Bryce (ed.). Indianápolis: Liberty Fund, 1985 [Oxford University Press, 1983].

(RN) An Inquiry into the Nature and Causes of the Wealth of Nations [WN, 1776]. R. H. Campbell y A. S. Skinner (eds.). Indianápolis: Liberty Fund, 1981 [Oxford University Press, 1976, 1979].

(TSM) The Theory of Moral Sentiments [TMS 1759]. D. D. Raphael y A. A. Macfie (eds.). Indianápolis: Liberty Fund, 1984 [Oxford University Press, 1976, 1979].

\section{b) Otros autores citados}

Berry, Christopher J.: “Adam Smith: Commerce, Liberty and Modernity”. En P. Gilmour (ed.) Philosophers of the Enlightenment. Edimburgo: Edinburgh University Press, 1989.

"Adam Smith and the Virtues of Commerce". En J. Chapman y W. Galston (eds.), Virtue. Nueva York: New York University Press, 1992.

Social Theory of the Scottish Enlightenment. Edimburgo: Edinburgh University Press, 1997. 
- “Smith under Strain”. En European Journal of Political Theory, 3 (2004): 455463.

"Adam Smith and Science”. En Knud Haakonsen (ed.), Cambridge Companion to Smith. Cambridge: Cambridge University Press (en preparación).

Brown, Vivienne: Adam Smith's Discourse: Canonicity, Commerce, Conscience, Londres: Routledge, 1994.

Brubaker, Lauren: "A Particular Turn or Habit of the Imagination: Adam Smith on Love, Friendship and Philosophy”. En Eduardo Velásquez (ed.), Love and Friendship: Rethinking Politics and Affection in Modern Times. Lanham, MD: Lexington Books, 2003.

Buckle, Stephen: “Hume’s Biography and Hume’s Philosophy: 'My Own Life' and An Enquiry concerning Human Understanding”. En Australasian Journal of Philosophy, Vol. 77 № 1 (1999): 1-25.

- Hume's Enlightenment Tract: the Unity and Purpose of An Enquiry Concerning Human Understanding. Oxford: Oxford University Press, 2003.

Carrasco, María Alejandra: “Adam Smith’s Reconstruction of Practical Reason”. En The Review of Metaphysics, 58 (2004): 81-116.

Cremaschi, Sergio: “Adam Smith: Skeptical Newtonianism, Disenchanted Republicanism, and the Birth of Social Science”. En M. Dascal y O. Grunengard (eds.), Knowledge and Politics: Case Studies in the Relationship between Epistemology and Political Philosophy. Boulder CO: Westview Press, 1989.

Cropsey, Joseph: Polity and Economy: an Interpretation of the Principles of Adam Smith. La Haya: Nijhoff, 1957.

D’Alembert, Jean le Rond: Preliminary Discourse to the Encyclopedia of Diderot. Chicago: University of Chicago Press, 1995.

Darwall, Stephen: “Empathy, Sympathy, and Care”. En Philosophical Analysis, 89 (1998): 2-3.

"Equal Dignity in Adam Smith”. En Adam Smith Review, 1 (2004): 129-134.

Dent, N. J. H.: Rousseau. Oxford: Blackwell, 1988.

Fleischacker, Samuel: A Third Concept of Liberty: Judgement and Freedom in Kant and Adam Smith. Princeton NJ: Princeton University Press, 1999.

- On Adam Smith's Wealth of Nations: A Philosophical Companion. Princeton, NJ: Princeton University Press, 2004.

Force, Pierre: Self-interest before Adam Smith: A Genealogy of Economic Science. Cambridge: Cambridge University Press, 2003.

Forman-Barzilai, F.: "Smith on 'Connexion', Culture and Judgement”. En L. Montes y E. Schliesser (eds.), New Voices on Adam Smith. Routledge, 2006.

Frasca-Spada, Marina: Space and Self in Hume's Treatise. Cambridge: Cambridge University Press, 1998.

Gerschlager, Caroline: "Is (Self-)deception an Indispensable Quality of Exchange? A New Approach to Adam Smith's Concept”. En C. Gerschlager (ed.), Expanding the Economic Concept of Exchange: Deception, Self-deception and Illusions. Boston, MA y Dordrecht: Kluwer, 2002: 27-52.

Griswold, Charles L.: Adam Smith and the Virtues of Enlightenment. Cambridge: Cambridge University Press, 1999.

Haakonsen, Knud: The Science of the Legislator: the Natural Jurisprudence of David Hume and Adam Smith. Cambridge: Cambridge University Press, 1981. 
Hanley, Ryan: "Hume’s Last Lessons: The Civic Education of 'My Own Life”. En Review of Politics, 64 (2002).

“Capitalism and Corruption: Rousseau's Diagnosis and Adam Smith's Cure”. Manuscrito. (s/f.)

Heath, Eugene: “Mandeville's Bewitching Engine of Praise”. En History of Philosophy Quarterly, 15 (1998): 205-226.

Levy, David M.: “The Market for Fame and Future”. En History of Political Economy, 20 (1988): 615-625.

Economic Ideas of Ordinary People: From Preferences to Trade. Londres: Routledge, 1992.

"The Partial Spectator in the Wealth of Nations: a Robust Utilitarianism". En European Journal of the History of Economic Thought, Vol. 2 No 2 (1995): 299326.

Levy, David M. y Peart, Sandra J.: "Sympathy and Approbation in Hume and Smith: A Solution to the Other Rational Species Problem”. Por aparecer en Economics and Philosophy.

Livingston, Donald W.: Philosophical Melancholy and Delirium: Hume's Pathology of Philosophy. Chicago: University of Chicago Press, 1998.

Lomonaco, Jeffrey: "Adam Smith's Letter to the Authors of the Edinburgh Review". En Journal of the History of Ideas, 63 (2002): 659-676.

Margolis, Howard: It Started with Copernicus: How turning the World Inside Out Led to the Scientific Revolution. Nueva York: McGraw-Hill, 2002.

Millican, Peter (ed.): Reading Hume on Human Understanding. Oxford: Oxford University Press, 2002.

Mirowski, Philip: More Heal than Light: Economics as Social Physics, Physics as Nature's Economics. Cambridge: Cambridge University Press, 1989.

Montes, Leonidas: "Smith and Newton: Some Methodological Issues Regarding General Economic Equilibrium Theory”. En Cambridge Journal of Economics, 27 (2003): 723-747.

Adam Smith in Context: A Critical Reasessment of Some Central Components of his Thought. Londres: Palgrave MacMillan, 2004.

"Adam Smith: Real Newtonian and Supposed Father of General Economic Equilibrium Theory”. En Sheila Dow y Alistair Dow (eds.), History of Scottish Political Economy. Londres: Routledge, 2006.

Newton, Isaac: The Principia: Mathematical Principles of Natural Philosophy. Traducción de Bernard Cohen y Anne Whitman. Berkeley, CA: University of California Press, 1999.

Otteson, James: Adam Smith's Marketplace of Life. Cambridge: Cambridge University Press, 2002.

Pack, Spencer: Capitalism as a Moral System: Adam Smith's Critique of the Free Market Economy. Brookfield, VT: Elgar, 1991.

"The Rousseau-Smith Connection: Towards an Understanding of Professor West’s ‘Splenetic Smith’”. En History of Economic Ideas, Vol. 8 No 2 (2000): 3562.

Peart, Sandra y Levy, David M.: From Equality to Hierarchy: 'The Vanity of the Philosofer' in Post-classical Economics”. Ann Arbor, MI: University of Michigan Press, 2005. 
Quine, W. V.: “Epistemology Naturalized”. En W. V. Quine, Onthological Relativity and Other Essays. Nueva York: Columbia University Press, 1969.

Rae, John: Life of Adam Smith. Londres: Macmillan, 1985.

Rosenberg, Nathan: "Some Institutional Aspects of the Wealth of Nations". En Journal of Political Economy, 68 (1960): 557-570.

Ross, Ian Simpson: The Life of Adam Smith. Oxford: Clarendon Press, 1995.

Rotschild, Emma: Economic Sentiments: Adam Smith, Condorcet and the Enlightenment. Cambridge, MA: Harvard University Press, 2002.

Schliesser, Eric: "The Obituary of a Vain Philosopher: Adam Smith's Reflections on Hume's Life”. En Hume Studies, Vol. 29 № 2 (2003): 327-362.

"Hume's Missing Shade of Blue, Reconsidered from a Newtonian Perspective". En Scottish Journal for Philosophy, Vol. 2 № 2 (2004): 164-175.

"Articulating Practices as Reasons: Adam Smith on the Social Conditions of Possibility of Property”. En Adam Smith Review, 2 (2005a).

"Some Principles of Adam Smith’s Newtonian Methods in Wealth of Nations".

En Research in History and Methodology of Economics, 23A (2005b): 35-77.

"Realism in the Face of Scientific Revolutions: Adam Smith on Newton's

'Proof' of Copernicanism”. Por aparecer en British Journal for the History of

Philosophy.

“Berkely’s Response to Newton” (en revisión-a).

"Hume’s Attack on Newtons Philosophy” (en revisión-b).

Schliesser, Eric y Spencer Pack: “Adam Smith's Humean Criticism of Hume's Account of Origin of Justice”. Por aparecer en Journal for the History of Philosophy.

Skinner, Andrew: A System of Social Science: Papers Relating to Adam Smith. Oxford, Clarendon Press, 2a edición, 1996.

Starobinski, Jean: Jean-Jacques Rousseau: Transparency and Obstruction. Traducción de Arthur Goldhammer e introducción de Robert J. Morrissey. Chicago: University of Chicago Press, 1988.

Stein, Howard: "Logos, Logic and Logistiké. Some Philosophical Remarks on Nineteenth Century Transformations of Mathematics”. En William Aspray y Philip Kitcher (eds.), Minnesota Studies in the Philosophy of Science XI. History and Philosophy of Modern Mathematics. Minneapolis, MN: University of Minnesota Press, 1988.

— "How Does Physics Bear on Metaphysics; and Why Did Plato Hold that Philosophy Cannot Be Written Down?”. (No publicado aún).

Strawson, Galen: "David Hume: Objects and Power”. En R. Head y K. Richman (eds.), The New Hume Debate. Londres: Routlege, 2000.

Uyl, D. J. den y C. L. Griswold, Jr.: “Adam Smith on Friendship and Love”. En Review of Metaphysics, 49 (1996): 609-637.

Wightman, D.: “Adam Smith and the History of Ideas”. En A. S. Skinner y T. Wilson (eds.), Essays on Adam Smith. Oxford: Clarendom Press Wilson, 1975.

Wright, John P.: The Sceptical Realism of David Hume. Minneapolis, MN: University of Minnesota Press, 1983. 